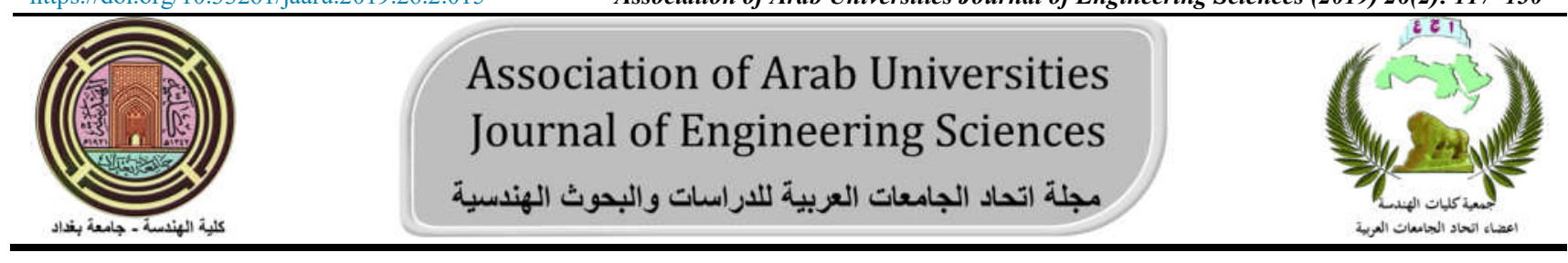

الدور المكننة في تحقيق التكامل و المرونة للقاعات متعددة الاستعمال

شهُ واقد صالح 1"، بهجت رشاد شاهين2

1ق قسم هنسة العصارة، جامعة بغداد، العراق، arch.shahadwakid@gmail.com

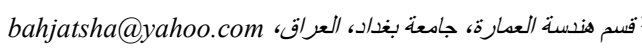

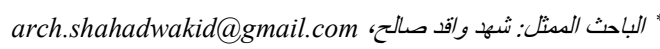

نشر في: 30 حزيران 2019

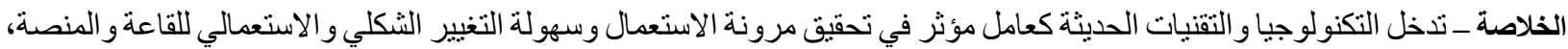

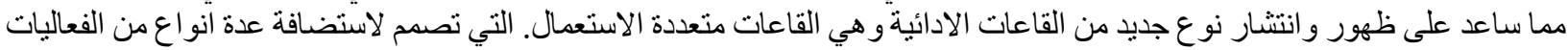

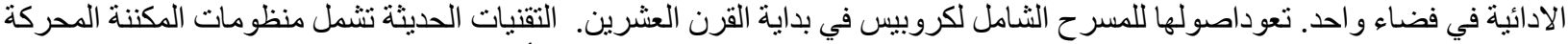

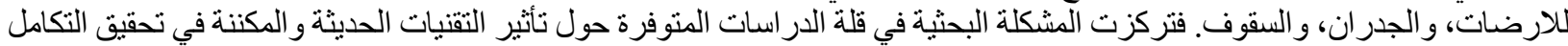

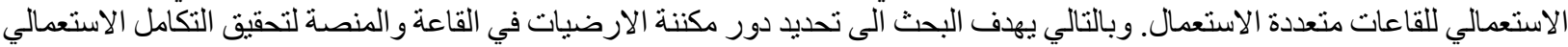

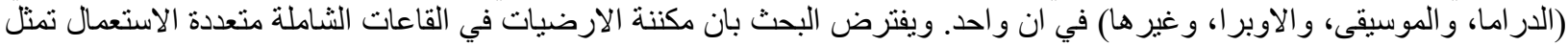

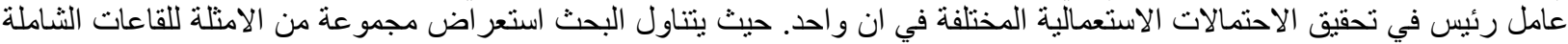
متعددة الاستعمال في القرن العشرين، و القرن الواحد والعشرين. كما يوضح البحث نطور هذا النوع من القاعات وأثر المكننة والتطور التكنولوجي عليها. الكلمات الرئيسية ـ القاعات متعددة الاستعمال، التقنيات الحديثة، الدكنذة ومنظوماتها.

2.

العامل الاقتصادي: وما توفرة من كلف التصميم و التشييد. فضلا

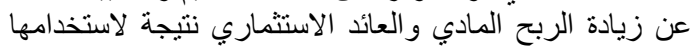

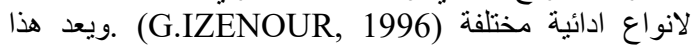
العامل مهح جدا للو اقع العر اقي.

انخفاض معدلات تشغيل واستغلال الابنية الادائية احادية

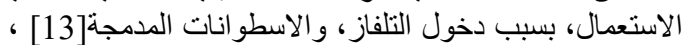

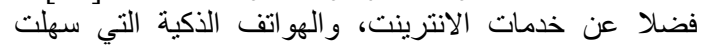

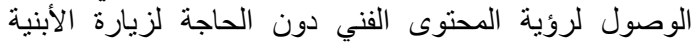

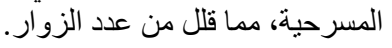

لكونها تقدم عروض مختلفة فأنها تلبي مختلف الرغبات و الاذو اق،

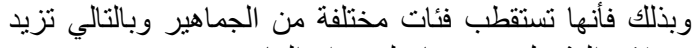
معدلات التشغيل وتنو عها على مدان مدار العام.

التطور التكنولوجي المتنامي و المتطور في مجال البناء و الانشاء، التئاء

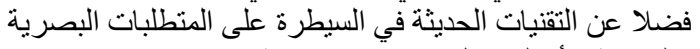

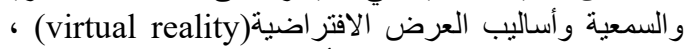

التي سهلت تحقيق التوازن بين الأنماط الوظيفية المختلفة.

\section{مكنتة المنصة المسرحية متعددة الاستعمال}

تساعد المكننة المستخدمة في المنصة المسرحية على تغيير المشاهد

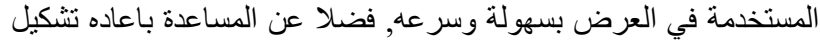

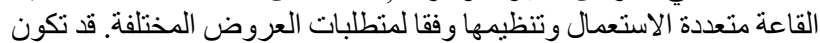

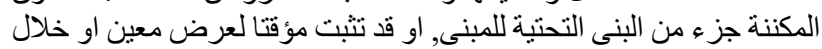

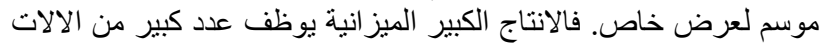

1

هي القاعات التي لها القابلية على التحول، ذات منصة متعددة

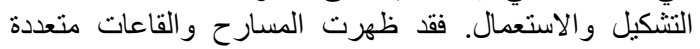

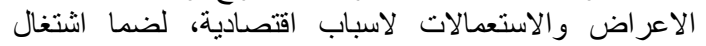
و استعمال القاعة بالثكل الكافي ولتحقيق اثل إنفاق لراس المالـ المال .

هي القاعات التي لها القابلية على التغيير الثكلي والصوتي التياء

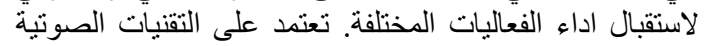

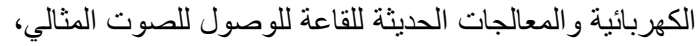

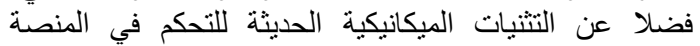

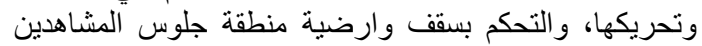

لتغيير الطاقة الاستيعابية للقاعة. [2]

تعريف القاعات متعددة الاستعمال وفقا للاراسة الحالية: هي

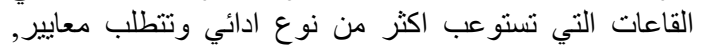

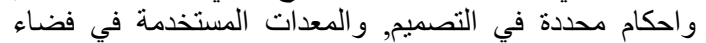

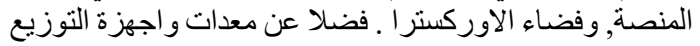

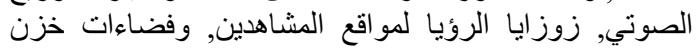

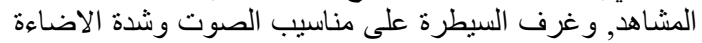

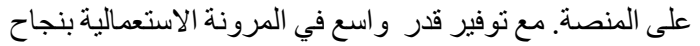

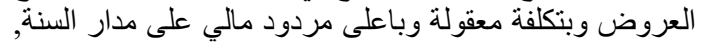

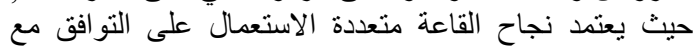

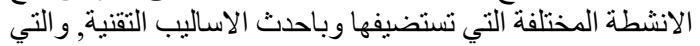
تعد ملائمة جدا للو اقع العر اقي المحلي. 
يوضح الشكل نظام الحركة الهيدروليكية لمقاطع منصة المنصة عموديا باستخدام المساند بانو اعها المختلفة (المصاعد الهيدروليكية) [16 لئهية
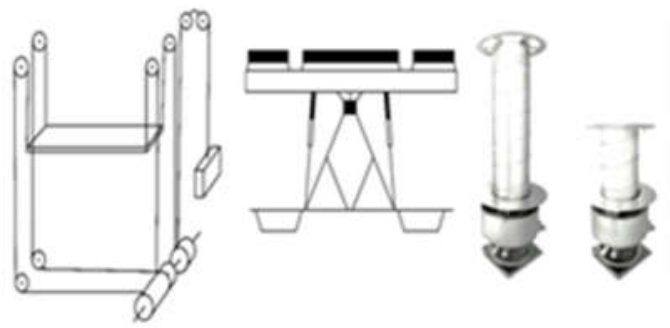

a . مصعد ذو الدوامه الدوارة وهو من المصاعد المعتمدة في الكثير من

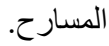
b

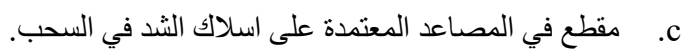
الثكل (2): يوضح المصاعد المستخدمة في المسرح (المصاعد الماعدي الهيدروليكية والمصاعد الالكترونية). [16 المئية

هنالك عده أنو اع لمصاعد المنصة: حسب المصدر [16]

المصعد المنفرد: يتكون بشكل عام من أرضية واحدة مستقلة، الا انها

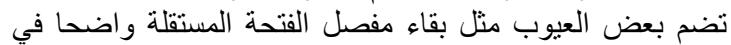

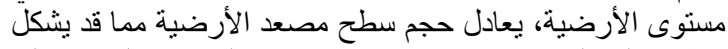

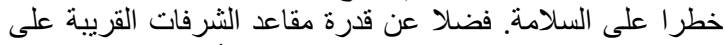
الرؤية، وسماع مناسيب الضوضلاء القادمة من أسفل العنبر.

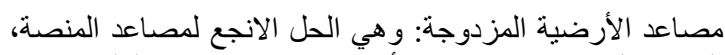

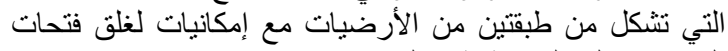
المصاعد على المنصة اثناء العرضئ من الارضيات

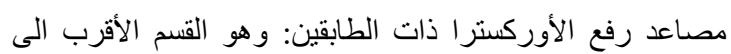

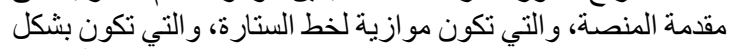

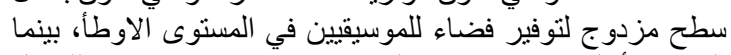

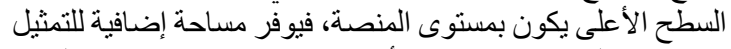

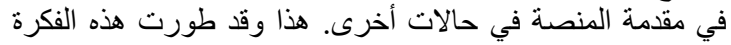

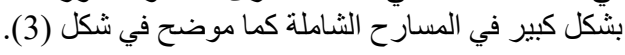

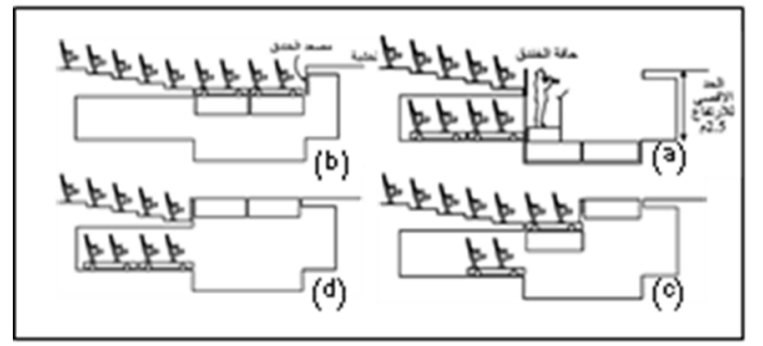

يوضح تخزين مسطبة مقاعد الجلوس الامامية المتحركة في مستوى

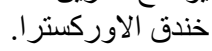
رفع مسطبة مقاعد الجلوس الامامية المتحركة حيث تحل محل الخندق .

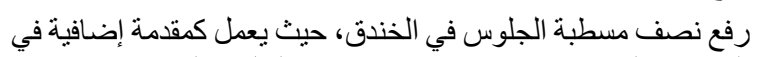
المنصة و النصف الاخر يرفع عربة مقاعد الجلوس لمستوى الارضية

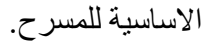
كل مساطب الخندق تعمل كمقدمة للمنصة مع غلق الخندق وخزن عربه المقاعد أسفل الأرضية. (APPLETON, 2008, p. 151) الثكل (3): قابلة التغيير هادروليكيا في خندق الاوركستر ا وتفاصيل الارضيات المتحركة افقيا وعموديا.

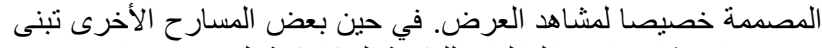

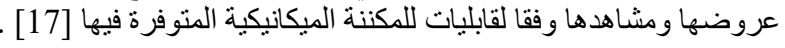

$$
\text { ومن أنو اع مكننة المنصة المتوفرة في المسارح هي: }
$$

الارضيات المتصركة

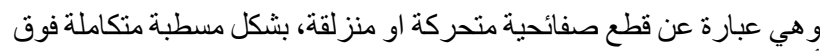

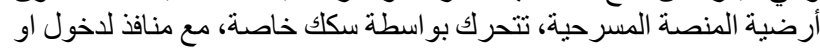

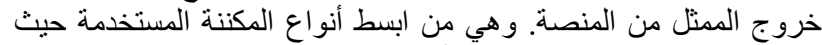

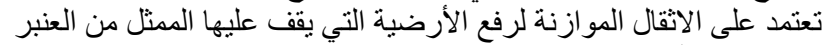

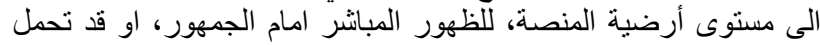

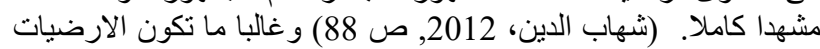

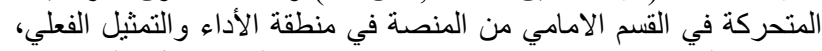

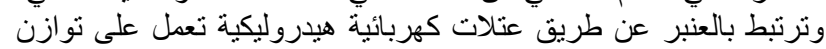

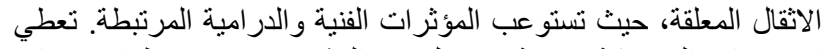

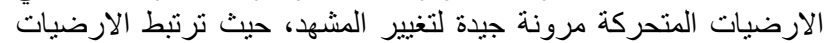

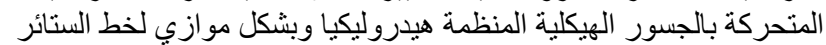

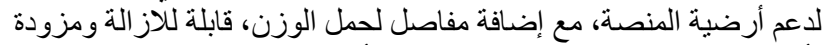
بأجهزة ربط مناسبة لتحقيق الاستقر ار والأمان لارضية المنية المنة. [10] كما

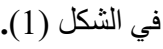

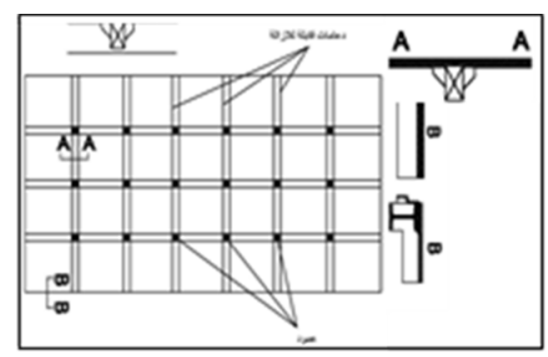

الشكل (1): مخطط ومقطع يوضح الأرضيات [16] المتحركة في المنصة

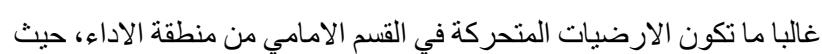

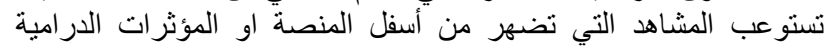
المرتبطة بالفنانين.

\section{المصاعد الهبيزروليكبة تحت المنصة}

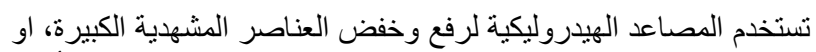

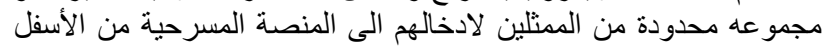

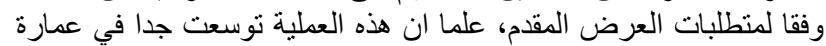

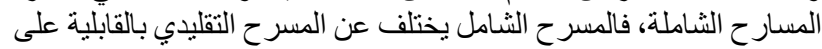

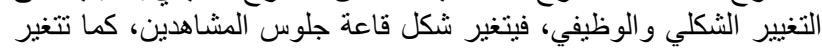

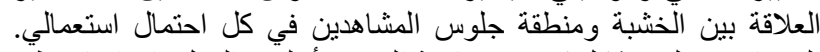

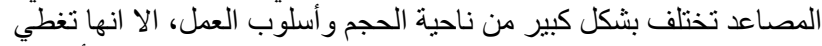

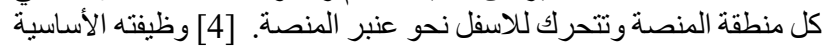

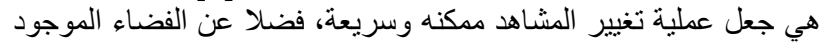

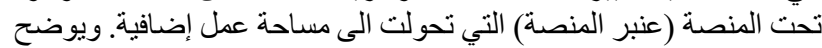

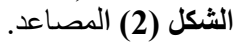

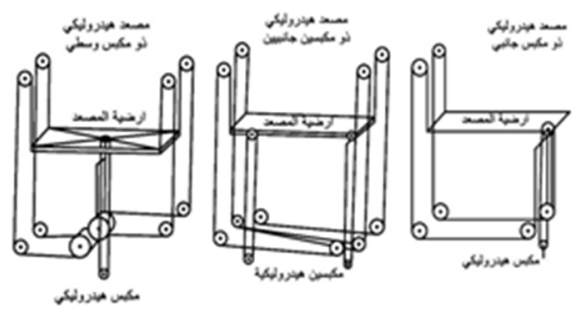




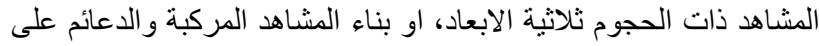

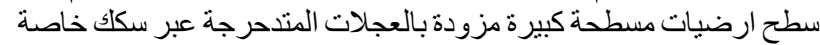

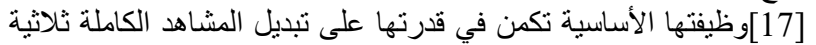

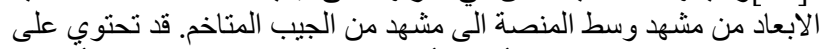

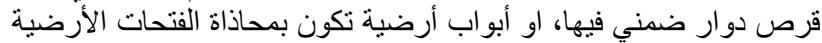

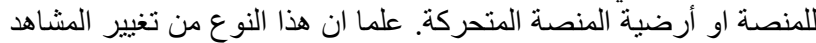
يعتمد في معظم المسار ح العالمية. تكون مسطحات المشاهد المتدحرجة على عدة أنواع:

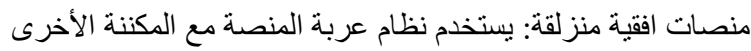
للمنصة لتوفير المرونة و الكفاءة، كما في اوبر الفنة المتروبولتنان.

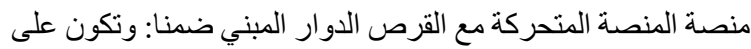

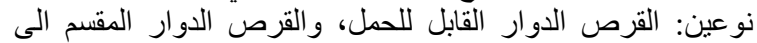

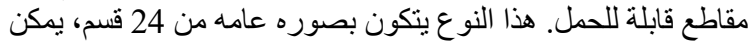
ان يعمل كل قسم بشكل منفرد.

جميع التقنيات الميكانيكية المذكورة تعمل على اسناد العرض الادائي المقدم

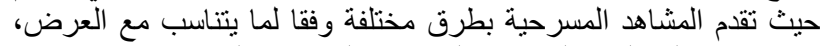

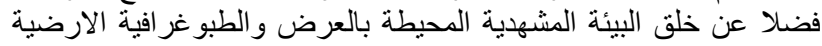

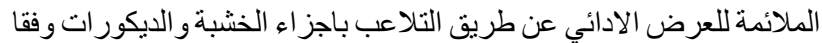

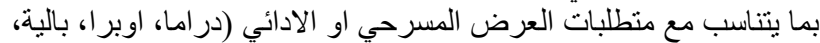

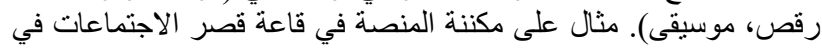

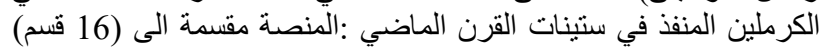

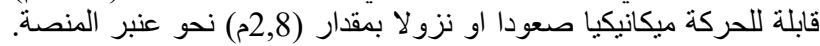

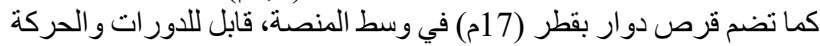

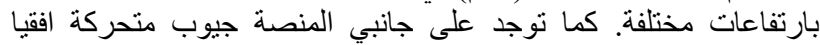

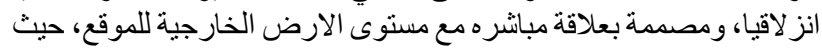

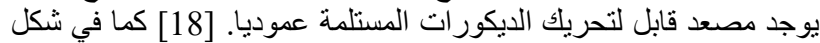

(6) (6) ، وشكل مدعد تابل

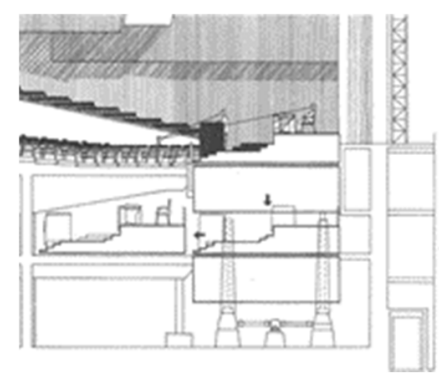

الثكل (6): يوضح منظومة المقاطع المتحركة الثناث لمقدمة المنصةة،

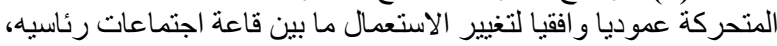

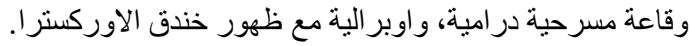

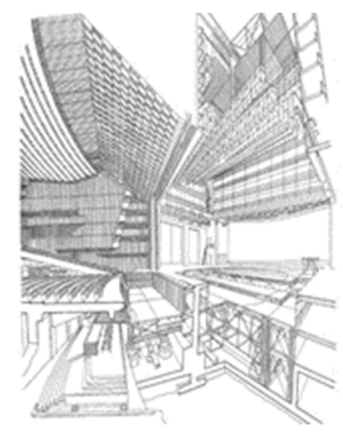

الثكل (7): منظور في القاعة يوضح المنصة و المنظومة الميكانيكية لها حول تغيير الاستعمال.

اما مقدمة المنصة فتكون متغيرة الابعاد، ففي حاله الاجتماعات الدولية والمحلية العليا تكون بابعاد(14*32م)، وفي حالة الفيرة الفعاليات المسرحية التية
كما تعتمد ميكانيكية عمل المصاعد في المنصة على حركتين:

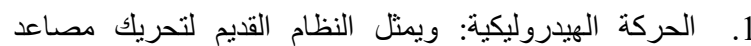

المنصة، حيث تعمل بو اسطة مكابس عمودية في منتصف الرئ أرضية

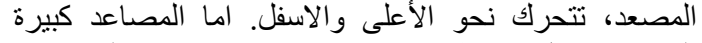

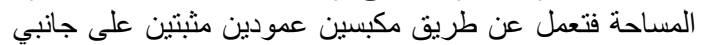

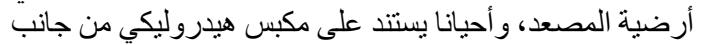

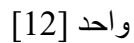

2. الحركة الالكترونية: وهي منظومة أحدث من منظومة الحركة

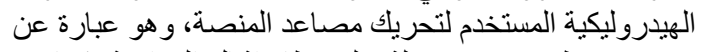

مصعد بسيط يعتمد في عملة على نظام اثقال الموازنة. كما في المئي

(2) الثكل (2).

القرص الدوار

وظيفته الأساسية هي اظهار صور مختلفة للمشاهدين عن طريق مخطط

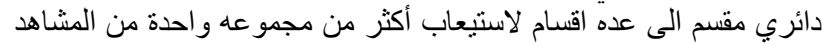

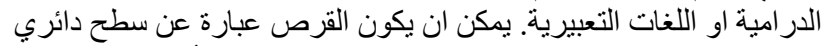

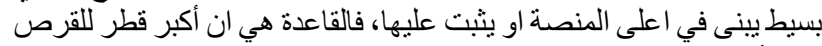

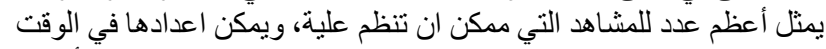

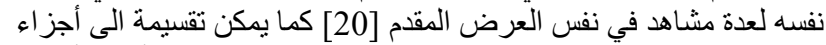

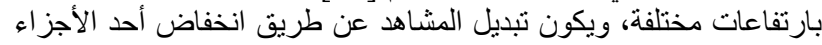

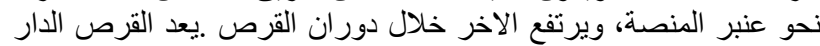

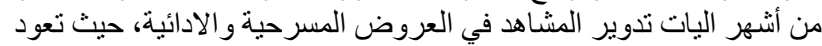

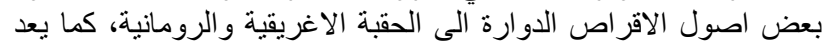

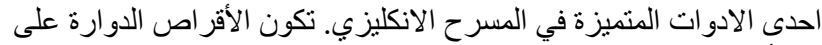

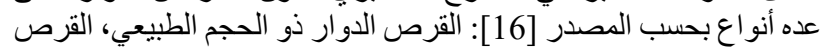

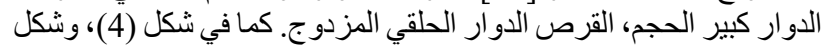

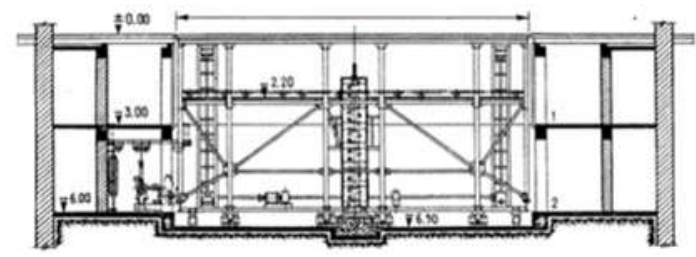

الثكل (4): مقطع في المنصة ذات القرص الوسطي الدوار مع إمكانية

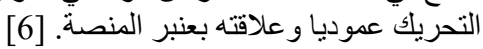

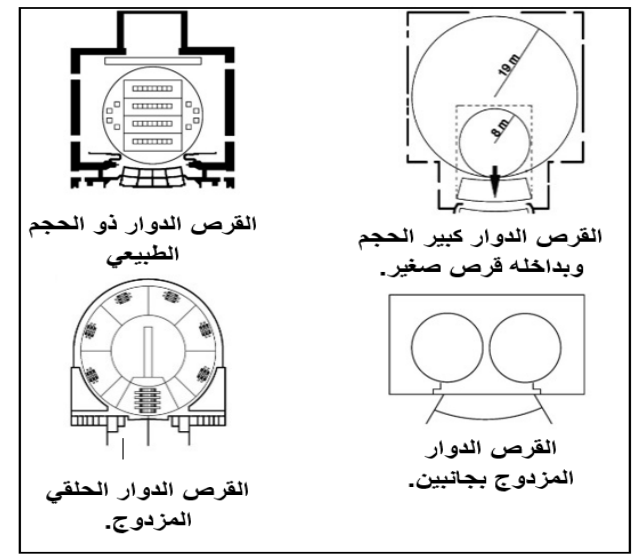

الثكل (5): انو اع القرص الدوار في المنصة (Ogawa, 2001)

3.4

يمكن تغيير المشاهد على المنصة عن طريق دحرجتها لمنصات جانبية في

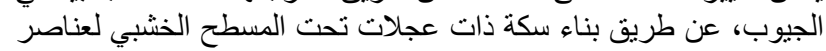




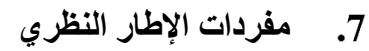

بعد استعر اض المعلومات أعلاه ثم التوصل للصيغة النهائية، للقاعدة

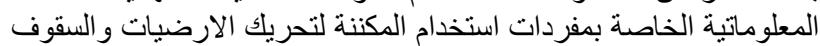

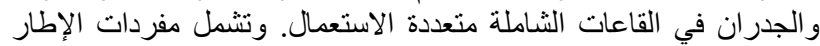

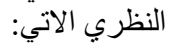

(اولا) المفردة الاولى: استخدام المكننة في التغيير الاستعمالي:

تتناول هذه الفقرة در اسة مؤشر ات الإمكانيات، و القابليات التي توفر ها المكننة

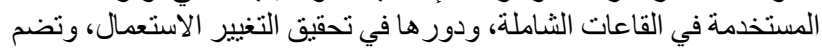

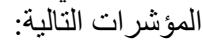

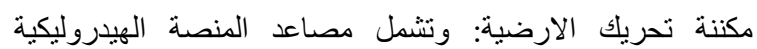

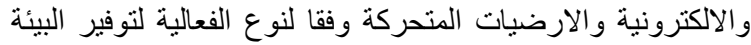

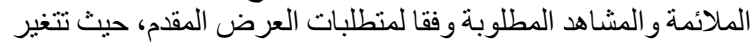
وفقا للفعالية الاستعمالية للقاعة.

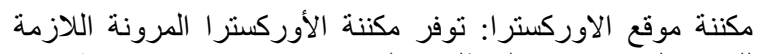

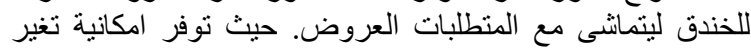

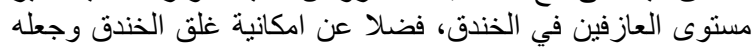

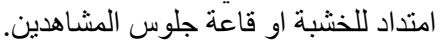

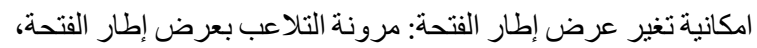

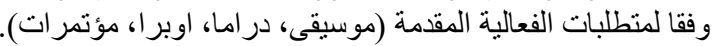

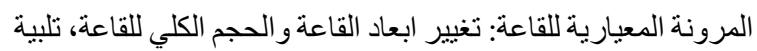

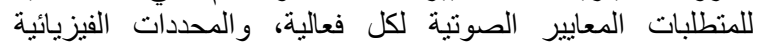

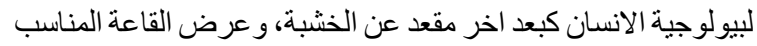
لكل فعالية.

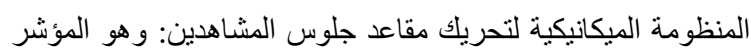

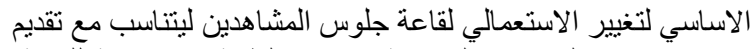

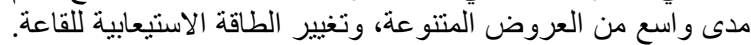

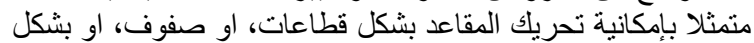

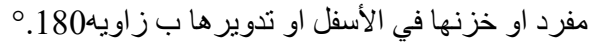

(ثانيا) المفردة الثانية: امكانية التغيير الاستعمالي:

تتناول هذه الفقرة اهم مؤشرات استعمال القاعة لتناسب فعاليات متعددة

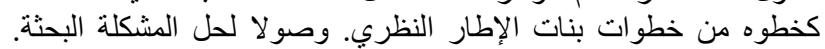
وتشمل المؤشر ات التالية:

منظومة تحريك السقف: لتلاعب بحجم القاعة وحسب المعايير المعتمدة

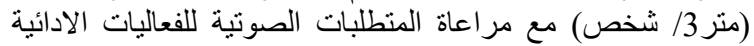

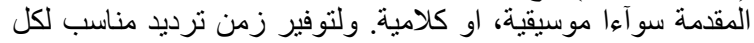
فعالية.

تغيير نسب المو اد الماصة و المواد العاكسة لضمان التوزيع الصوتي:

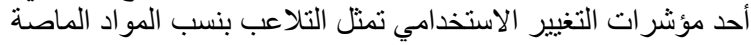

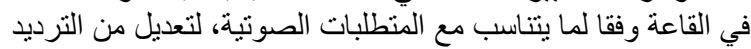

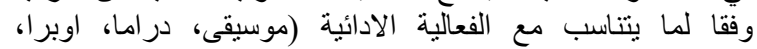
مؤتمر ات). تونات

امكانية تحريك زو ايا واشكال الجدران الجانبية و الخلفية وفقا للفعالية:

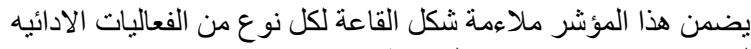
لضمان توفير الانعكاسات الملائمة.

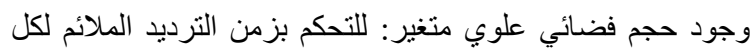

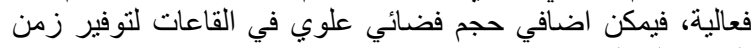

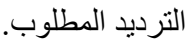

انظمة التعديل الصوتي: حيث استخدام الانظمة الالكتروصوتية الصنابة للتنلاعب بالحالة الصوتية للقاعة وفقا لنوع العرضي العرض المقدم ومتطلباته الكترونيا.

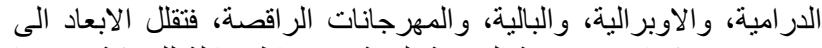

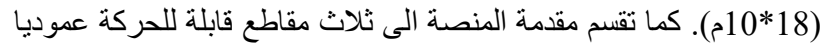

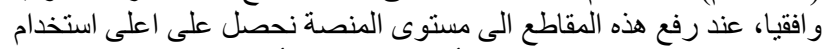

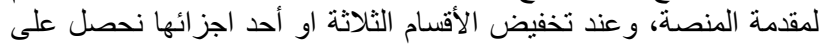

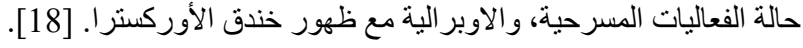

\section{مكنتة منطقة جلوس المشاهدين}

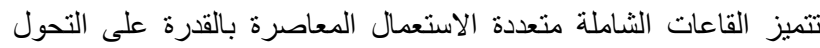

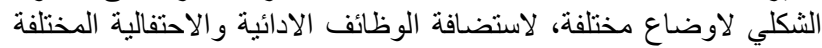

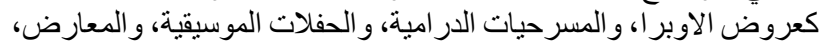

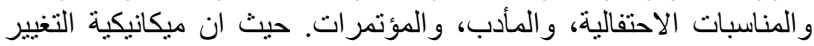

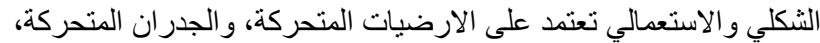

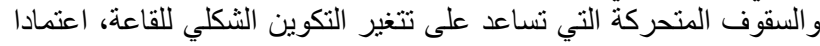

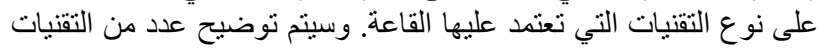
في العينات الدر اسية المنتخبة.

\section{5.}

تتميز منظومة السقف في القاعات متعددة الاستعمال بقابليتها على الحركة

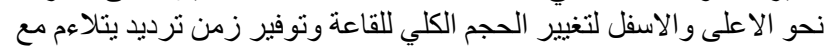

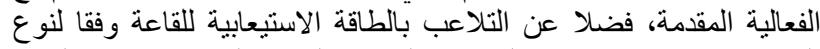

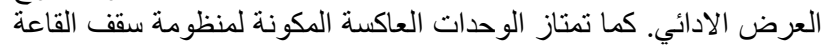

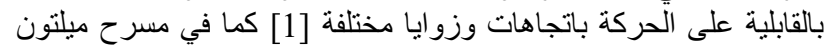

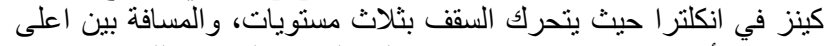

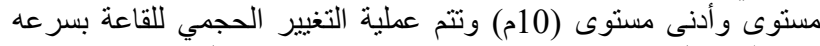
وسهولة خلال دقائق. (Orlowiski, 2010) كما في شكل 8.

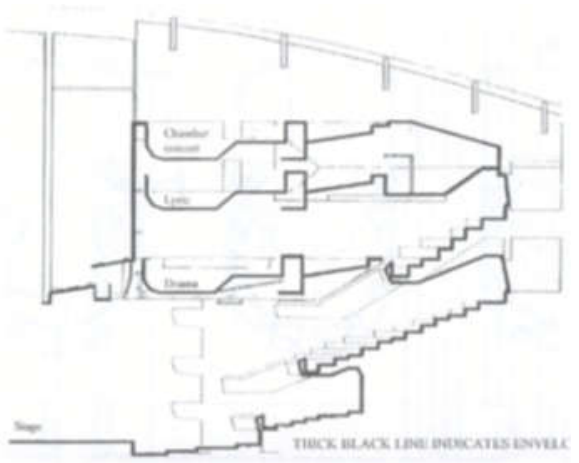

الثكل (8): يوضح موضع السقف في الحالات الاستخدامية المختلفة لقاعة

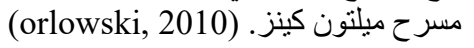

6. منظومة المواد الماصة المتغيرة في القاعات متعددة الاستعمال

تعد المواد الماصة، والعاكسة، والمبعثرة المتغيرة الاكثر استخداما، لتغيير

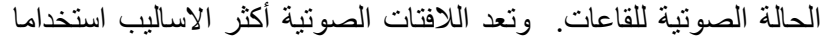

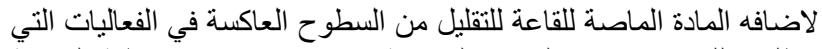

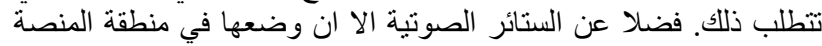

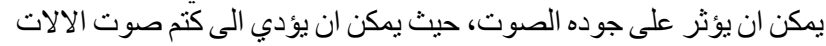

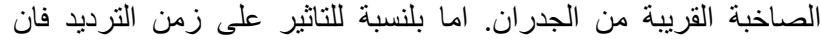

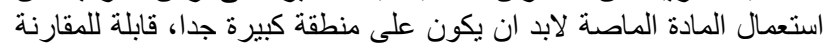

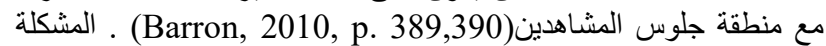

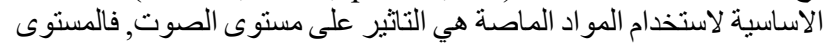

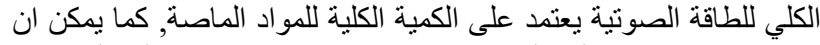

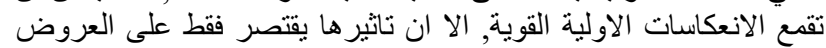
الكلامية. 
جدول (1): مفردات ومؤشرات الإطار النظري. (الباحثة)

\begin{tabular}{|c|c|c|c|c|c|c|c|c|}
\hline \multicolumn{5}{|c|}{ 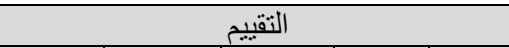 } & \multirow[t]{2}{*}{ 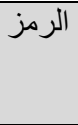 } & \multirow[b]{2}{*}{ مقومات المؤشر } & \multirow[b]{2}{*}{ مؤشر ات القيم الممكنة } & \multirow{2}{*}{ 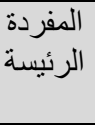 } \\
\hline ضيف & ض ضعيف & متوسط & 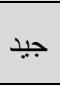 & جيدا & & & & \\
\hline & & & & & 1.1 & 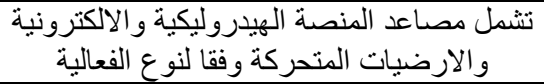 & مكننة تحريك الارضيات & \\
\hline & & & & & 1.2 & 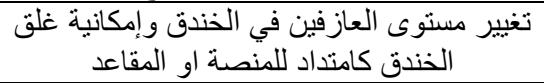 & مكننة موقع الأوركستر ا & \\
\hline & & & & & 1.3 & لتلبية نوع الفعالية & إمكانية تغيير عرض اطار & 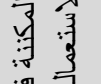 \\
\hline & & & & & 1.4 & المعايير البعدية للقاعة وحسب نوع الفعالية & المرونة المعيارية للقاعة & \\
\hline & & & & & 1.5 & إمكانية تحريك قطاعات جلوس المشاهدين او تدوير ها نحو الاسفل & 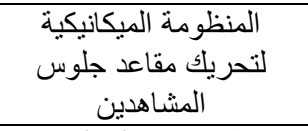 & \\
\hline & & & & & 2.1 & لتغير حجم القاعة وتوفير زمن اللئية للقاعة الترديد المناسب & منظومة تحريك السقف & \\
\hline & & & & & 2.2 & 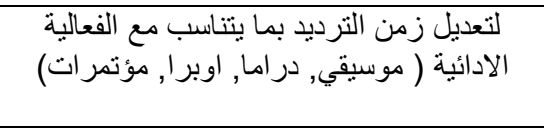 & و المواد العاكسة الضو اد الماصنة & 高. \\
\hline & & & & & 2.3 & 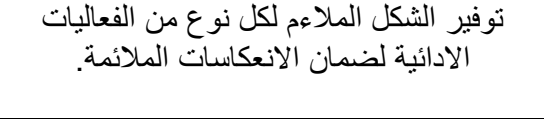 & 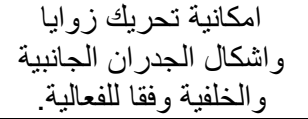 & 電: \\
\hline & & & & & 2.4 & المكانية اضافة حجم فضائية للتحكم بزمن الترديد المطلوب في القاعة & وجود حجم فضيائي علوي & $y:$ \\
\hline & & & & & 2.5 & 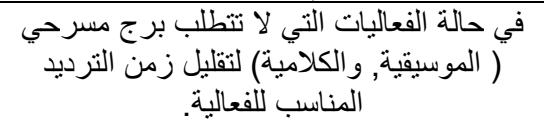 & المكانية عزل البرج & \\
\hline
\end{tabular}

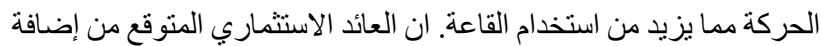

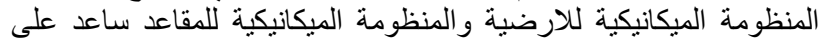

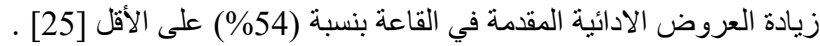

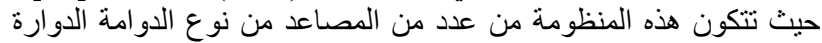

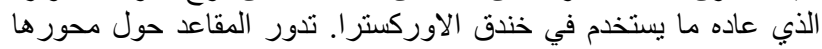

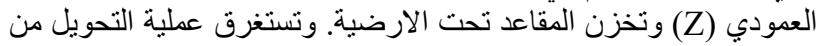

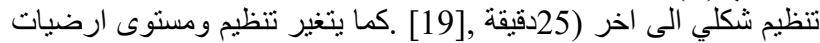

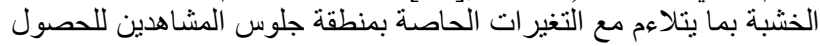

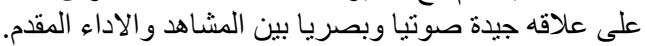

\section{الاحتمالات الاستعمالية للقاعة:}

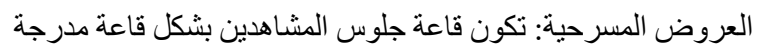

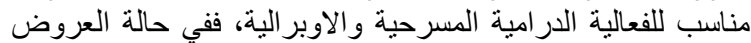

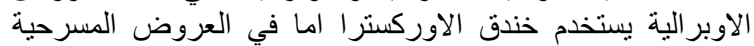

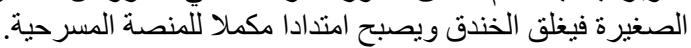

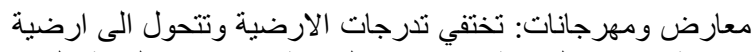

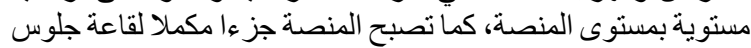

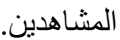

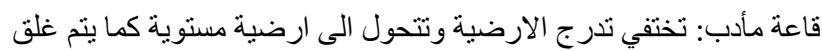

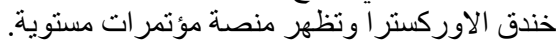

نادي ليلي: الارضية مدرجة الا ان التدرجات تكون اوسع من تدرجات

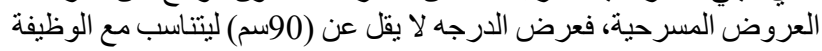
الاستخدامية

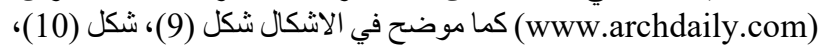
شكل (11)، شكل (12).
8

8.1

الموقع: يقع في مدينة سان انطونيو في ولاية تكساس، الولايات المتحدة

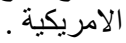

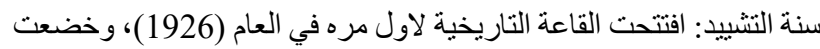

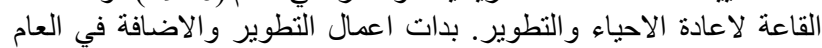

(2011) و افتتح في العام.(2014)

الجهه المصممة: صممت الاضافة الجديدة للمبنى من قبل شركة LMRCHITECTUR)

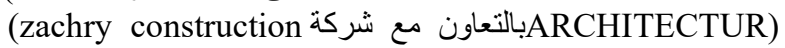
group).

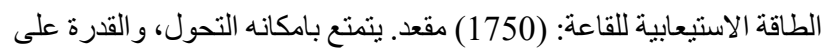

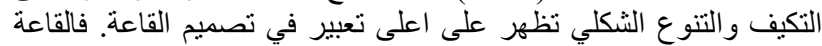

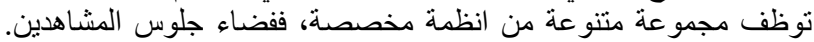

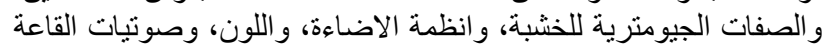

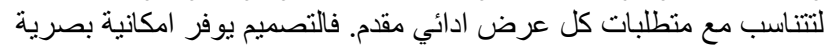

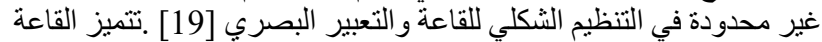

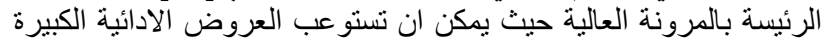

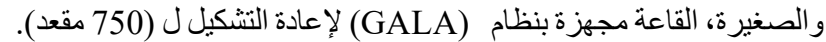

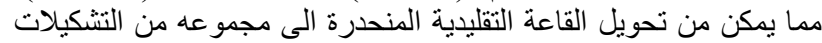

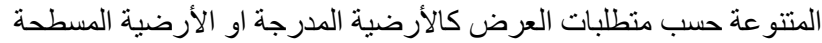

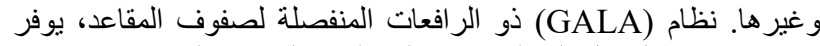

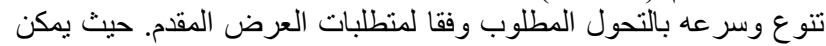

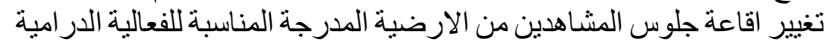

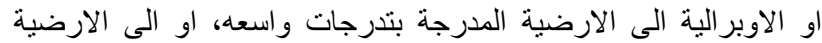

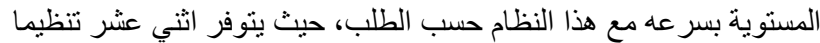

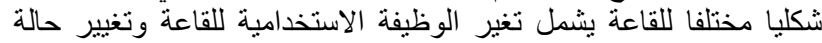
ارضية منطقة جلوس المشاهدين من حيث التدرج وتنظيم الوناعة المقاعد وممرات 

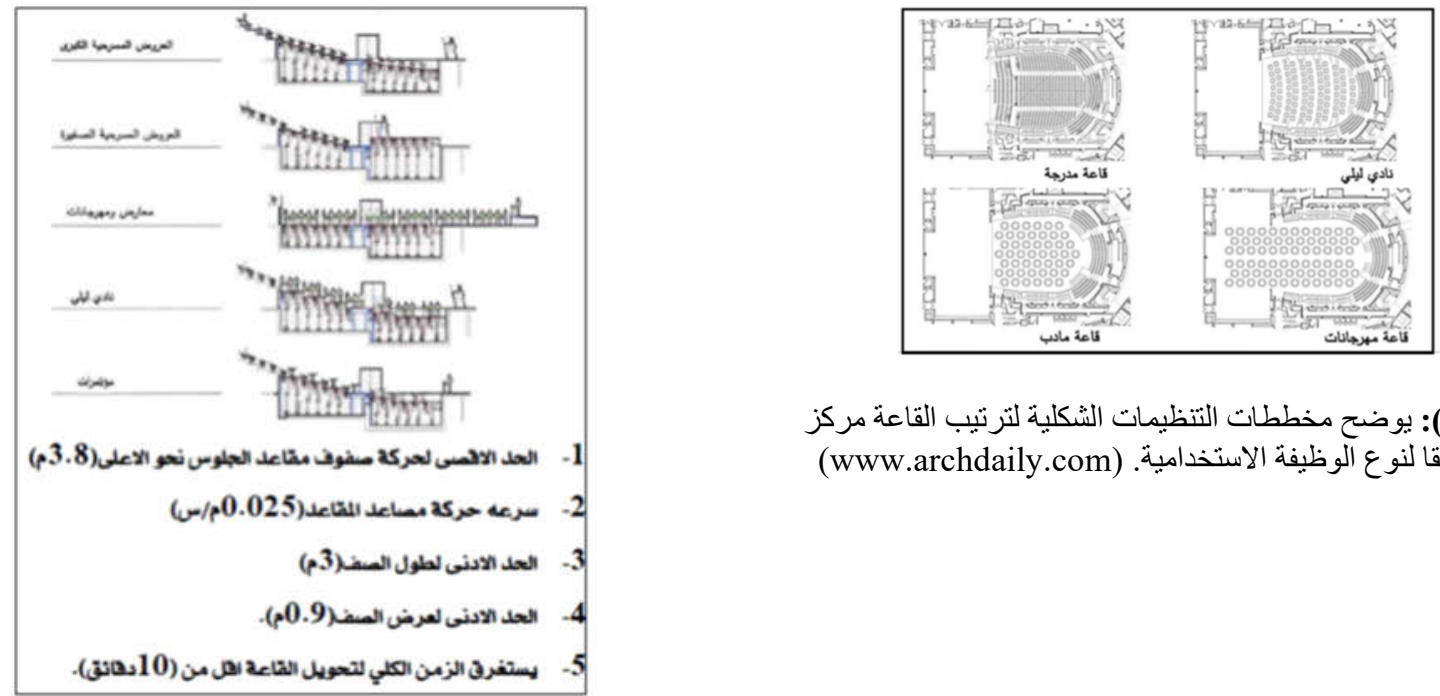

الثكل (9): يوضح مخططات التظظيمات الثكلية لترتيب القاعة مركز توبين وفقا لنوع الوظيفة الاستخدامية. (www.archdaily.com)

الشكل (10): يوضح المنظومة الميكانيكية لتحريك مقاعد صفوف

المشاهدين.

جدول (2): تطبيق مفردات ومؤشرات الإطار النظري على مركز نوبن. (الباحثة)

\begin{tabular}{|c|c|c|c|c|c|c|c|c|}
\hline \multicolumn{5}{|c|}{ التقييم } & \multirow[b]{2}{*}{ 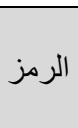 } & \multirow[b]{2}{*}{ مقومات المؤشر } & \multirow[b]{2}{*}{ مؤشر ات القيم الممكنة } & \multirow{2}{*}{ المئيسة } \\
\hline ضداف & ضعيف & متوسط & جيد & جيدا & & & & \\
\hline & & & - & & 1.1 & 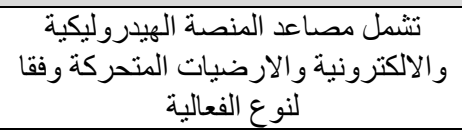 & مكننة تحريك الارضيات & $\overline{3}$ \\
\hline & & & - & & 1.2 & و إمكانية غلق الخندق كامتداد العازفين في الخندقة او & مكننة موقع الأوركستر ا & $y$ \\
\hline- & & & & & 1.3 & لتلبية نوع الفعالية & إمكانية تغيير عرض اطار الفتحة & 可 \\
\hline- & & & & & 1.4 & المعايير البعدية للقاعة وحسب نوع الفعالية & المرونة المعيارية للقاعة & 4 \\
\hline & & & & - & 1.5 & 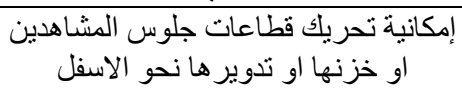 & المنظومة الميكانيكية لتحريك مقاعد & 3 \\
\hline & & - & & & 2.1 & 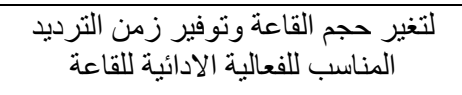 & منظومة تحريك السقق & \\
\hline & & - & & & 2.2 & لتعديل زمن الترديد بما يتناسب مع الفعائية & تغير نسب المو اد الماصنة والمواد التوزيع الصوتي & $\bar{g}$ \\
\hline - & & & & & 2.3 & 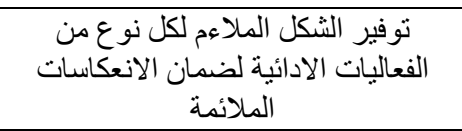 & 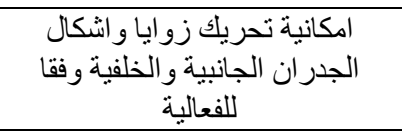 & : \\
\hline- & & & & & 2.4 & 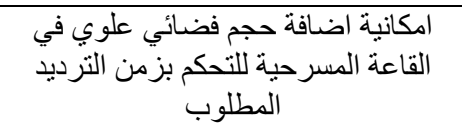 & وحجم حجم فضاءي علو متغير & 7 \\
\hline & & & & - & 2.5 & 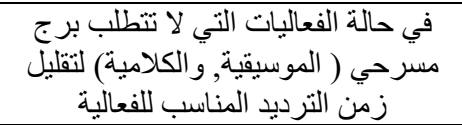 & امكانية عزل البرج المسرحي & \\
\hline
\end{tabular}




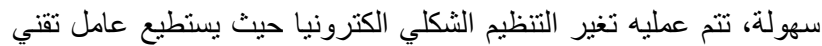

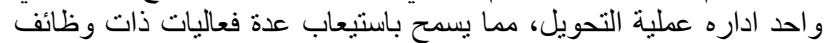
مختلفة في يوم واحد [25]

يتكون نظام (GALA) من عدد من صفوف المقاعد المستقلة ذات التوجيه

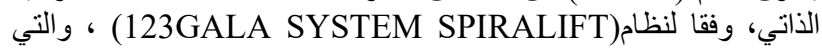

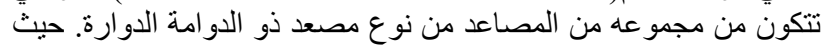

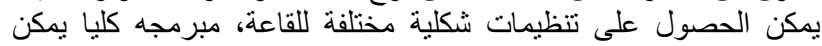

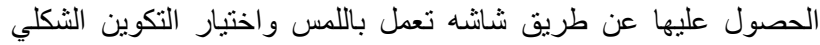

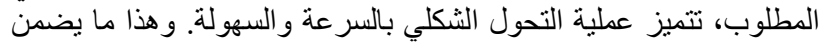

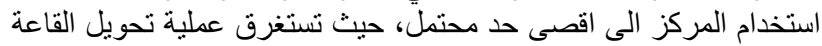

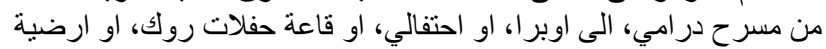

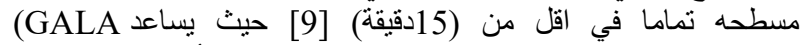
على ان تكون الفضاءات اقتصادية أكثر وذات مرات مرونة

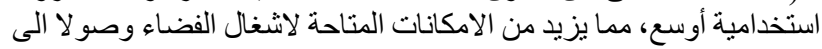

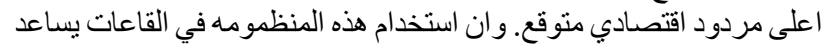

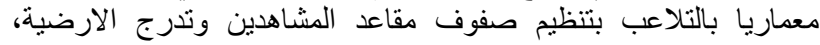

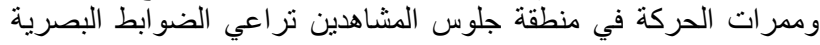

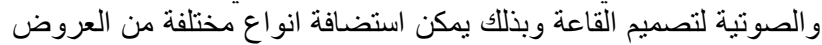

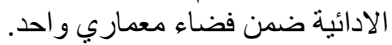

الاحتمالات الاستعمالية للقاعة:

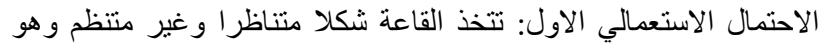
مناسب لعدد من الفعاليات الادائية، وبحسب الإنب الطاقة الاستيعابية المطلوبة

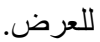

الاحتمال الاستعمالي الثاني: تتخذ القاعة شكلا مروحيا، وهي

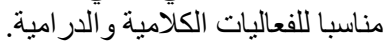

الاحتمال الاستعمالي الثالث: تتخذ القاعة شكلا يجمع بين الثكل

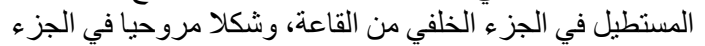

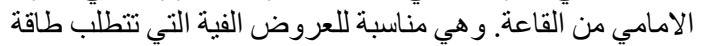

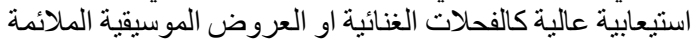

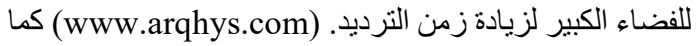

في شكل (13) وشكل (14).
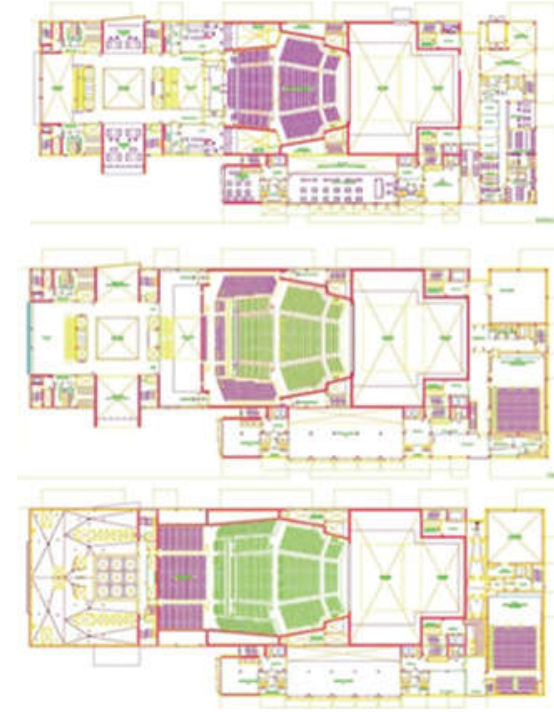

الثكل (13): يوضح التظيمات الثكلية الثلاث للقاعة، وامكانية عزل

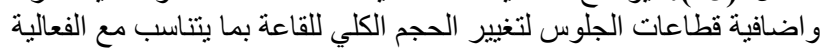
المقدمة (http://www.arqhys.com)

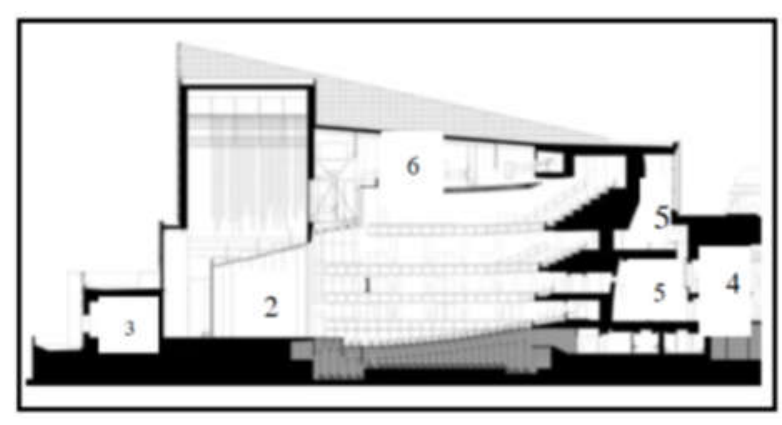

1. القاعة ومنظومة تحريم الارضيات، وموقع الاوركسترا.

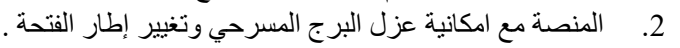
3. ت قاعة ثانوية صغيرة.

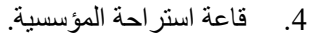
6.

الثكل (11): مقطع في قاعة توبين، سان اطونيو، تكساس امريكيا (www.archdaily.com)

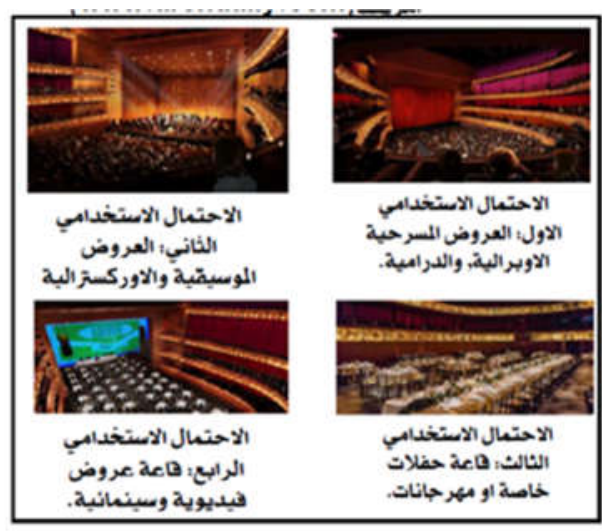

الشكل (12): الاحتمالات الاستعمالية لقاعة مركز توبين في سان انطونيو، تكساس، امريكا.

ركز الابتكار (التكنولوجي

8.2

الموقع: يقع في اشبيليا، في جزيرة لاكارتوجا، في اسبانيا. سنه التشييد: صمم المشروع وبدا تنفيذة في العام (2013) ونم افتتاح المركز في العام.(2013)

الجهة المصممة: شركة.(Garcia dieguez consulting) الطاقة الاستيعابية للقاعة: (2000 مقعد في حالة الارضية المدرجة 0350 مقعد في حالة الارضية المستوية في بعض الاستعمالات الموسيقية كالروك) .

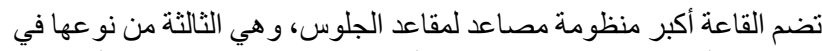

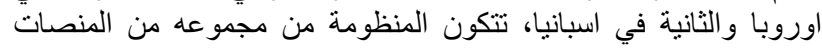

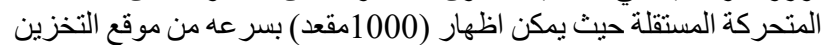

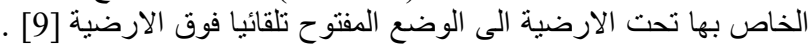
حيث اعتمد المركز

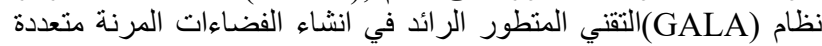

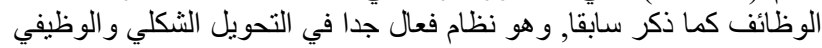

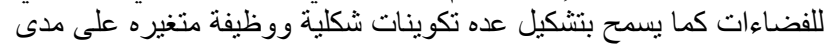
اليوم. وتستغرق مده التغيير الاستعمالي ما بين (40-10 دقيقة كمعدل) بكل بكل 


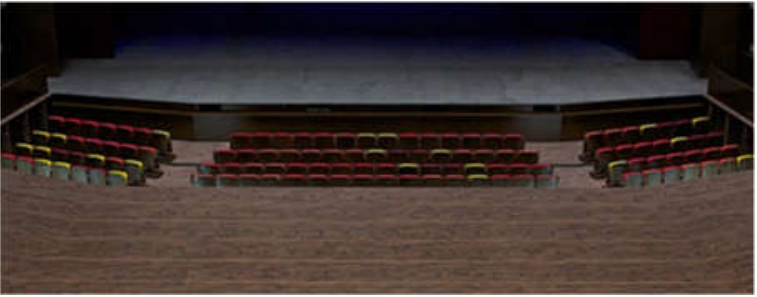

الثكل (15): نوضح الصورة حركة المقاعد نحو الاسفل وخزنها. وتحويل الارضية المدرجة اللى ارضية منبسطة.

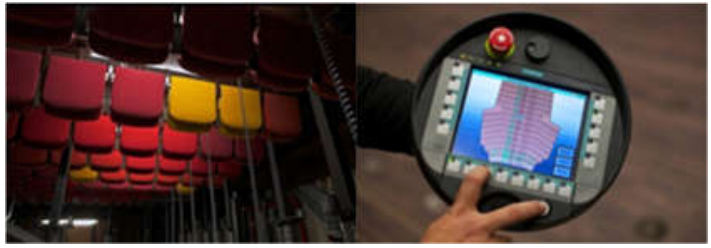

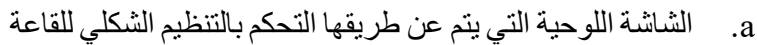
وتحويلها من ترتيب.

b ت توضح تقنية طي ودوران المقاعد نحو الاسفل وخزنها أسفل

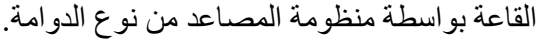

الثكل (14): المنظومة الميكانيكية لتحريك مقاعد الجلوس في مركز الابتكار

جدول (3): تطبيق مفردات ومؤشرات الإطار النظري على مركز الابتكار التكنولوجي. (الباحثة).

\begin{tabular}{|c|c|c|c|c|c|c|c|c|}
\hline \multicolumn{5}{|c|}{ التقييم } & \multirow[b]{2}{*}{ 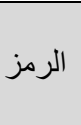 } & \multirow[b]{2}{*}{ مقومات المؤشر } & \multirow[b]{2}{*}{ مؤشر ات القيم الممكنة } & \multirow{2}{*}{ الرئيسة } \\
\hline ضديف & ضعيف & منوسط & جيد & جذا & & & & \\
\hline & & & & - & 1.1 & 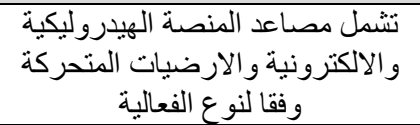 & مكننة تحريك الارضيات & $\overline{3}$ \\
\hline & & & & - & 1.2 & و إمكانية غلق الخندق العازفين في الخنداد للمنصة & مكننة موقع الأوركستر ا & $\bar{y}$ \\
\hline & & & & - & 1.3 & لتلبية نوع الفعالية & إمكانية تغيير عرض اطار & 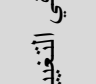 \\
\hline & & & & - & 1.4 & المعايير البعدية للقاعة وحسب نوع & المرونة المعيارية للقاعة & \\
\hline & & & & - & 1.5 & 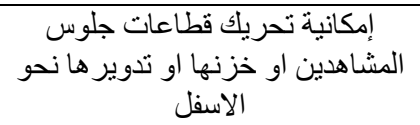 & $\begin{array}{c}\text { لتحريك مقاعد جلوس الميكانيكية } \\
\text { المشاهدين }\end{array}$ & \\
\hline & & & & & 2.1 & 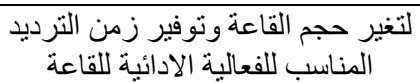 & منظومة تحريك السقف & \\
\hline & - & & & & 2.2 & لتعديل زمن الترديد بما يتناسب مع الفعادية & تو المو اد العاكسة الضو اد الماصمان & $\bar{g}$ \\
\hline- & & & & & 2.3 & 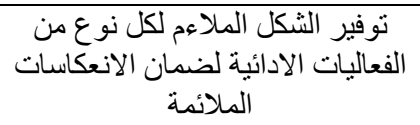 & و والثكال الجدرانية تحريك زوانيانية والجانبية & 電 \\
\hline & & - & & & 2.4 & 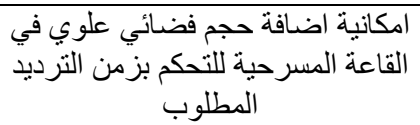 & وحجم حجم فضاءي متغير & ?. \\
\hline & & & & - & 2.5 & 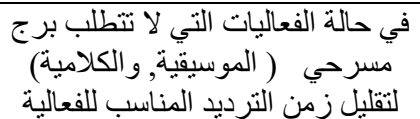 & المكانية عزل البرج & \\
\hline
\end{tabular}

الجهة المنفذة)(Consoildated Contractors Company) :

الطاقة الاستيعابية للقاعة: تصل الطاقة الاستيعابية للقاعة الى (2000) مقعد.

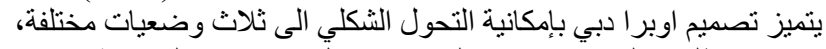

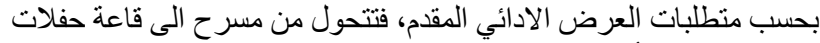

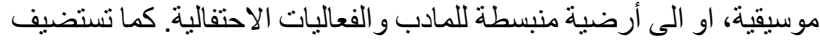

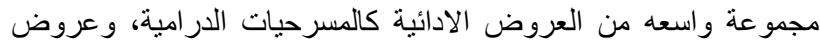

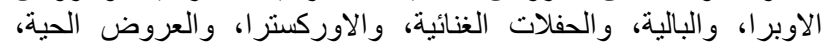

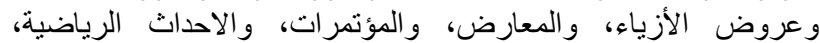

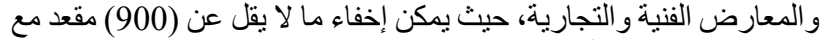

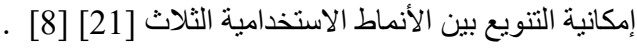

الموقع: تقع في قلب مدينة دبي في شارع محمد بن راشد وتطل على برج سنة التشييد: بدات اعمال التشييد في العام (2013)، و افتتح المبنى في العام

(2016).

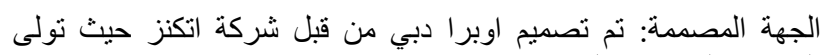

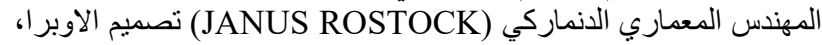
و هي قاعد متعددة التشكيل و الاستعمالات. 

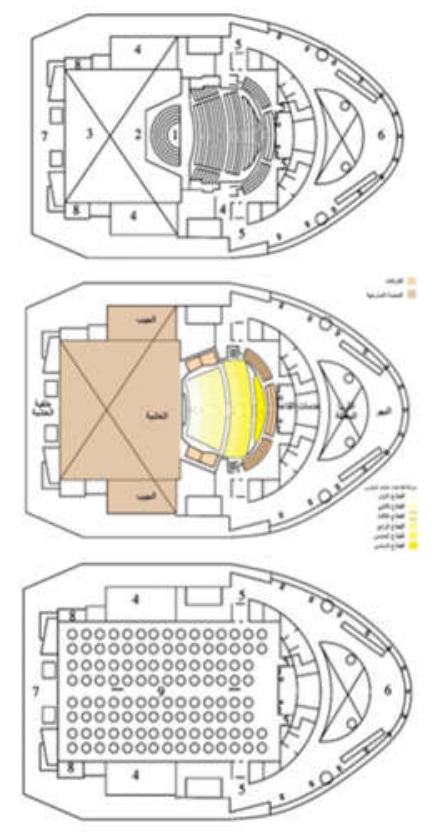

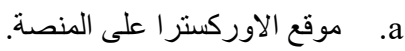

b ق قشرة الاوركسترا حيث تعزل الاوركسترا عن جيوب وخلفية d المنصة.

الشكل (17): مخططات الاحتمالات الاستخدامية الاساسية لاوبر الدبي

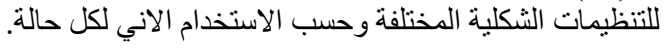

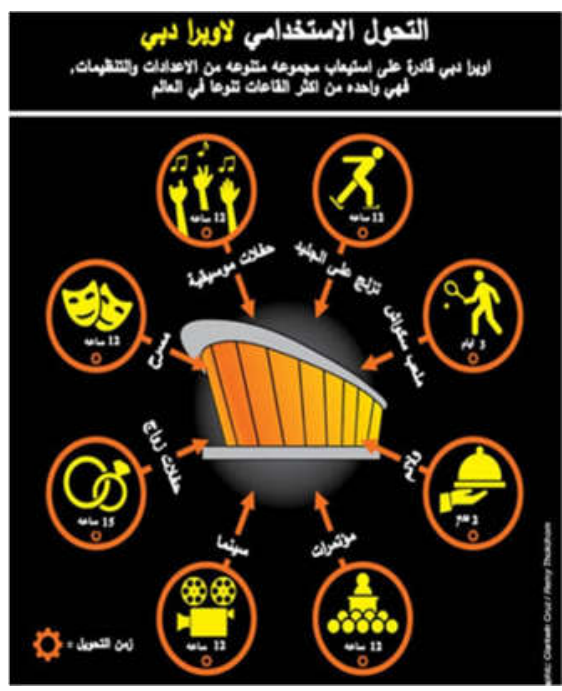

الثكل (18): الاحتمالات الاستخدامية الاجمالية

دار الاوبيرا السلطانية

8.4

الموقع: تقع دار الاوبرا السلطانية في العاصمة مسقط، في منطقة شط القرم،

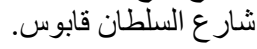

سنه التشييد: بدات اعمال التشييد في العام (2007)، و افتتح المبنى في العام

(2011).
الاحتمالات الاستعمالية للقاعة:

• الاحتمال الاستعمالي الأول (وضعية المسرح): تكون وضعية

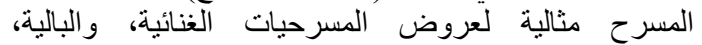

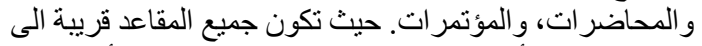

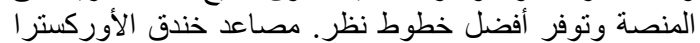

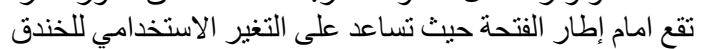

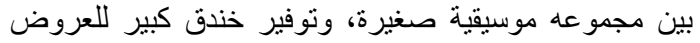

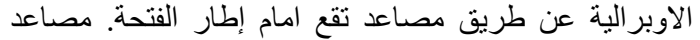

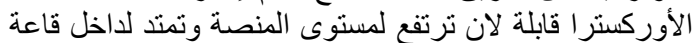

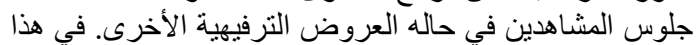
التنظيم الثكلي للقاعة تتخذ هاله القاعة شكلا مروحيا مناسبا للفعالية

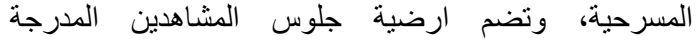

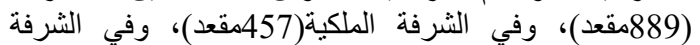

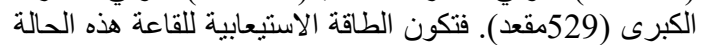

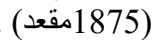

الاحتمال الاستعمالي الثاني: تتحول الى صالة لـالة للحفلات

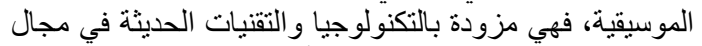

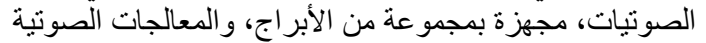

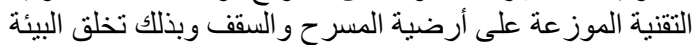

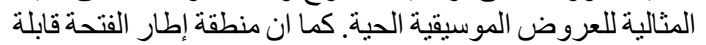

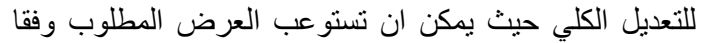

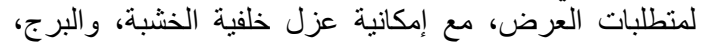

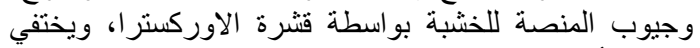

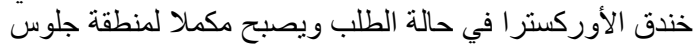
المشاهدين. في هذا التنظيم الثكلي يضم مستوى التئم الارضية

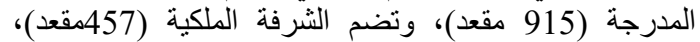
و الثرفة الكبرى (592مقعد)، فتكون الطاقة الاستيعابية الكلية

للقاعة(1901)

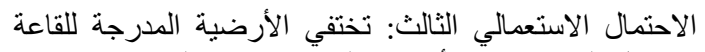

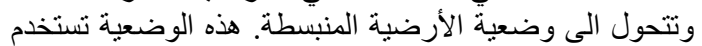

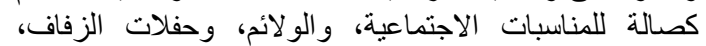

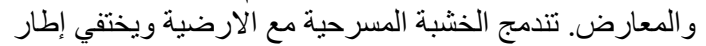

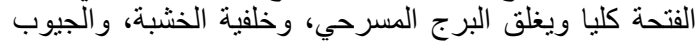

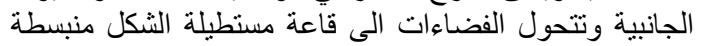

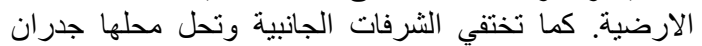
مسطحة عدا الثرفة الخلفية تبقى بارزه. (16) وشكل (17)، وشكل (18).

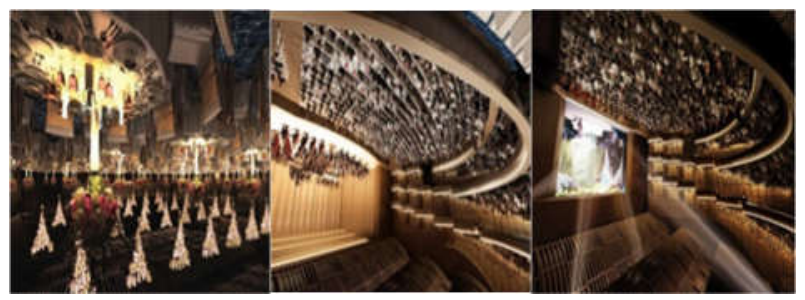

$$
\begin{aligned}
& \text { a } \\
& \text { b } \\
& \text { c الاحتمال الاستعمالي الثالث. }
\end{aligned}
$$

$$
\text { الشكل (16): الاحتمالات الاستخدامية لقاعه اوبر ادبي }
$$




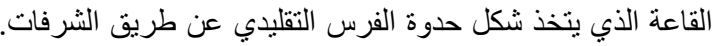

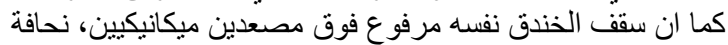

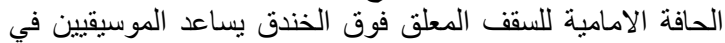

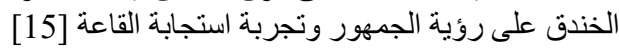
الاحتمال الاستعمالي الثاني: التغيير الشكلي في رونة الجية حالة الحفلات

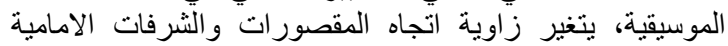

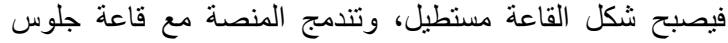
المشاهدين. التصميم الصوتي للقاعة يدعم الموسيقي الكئي الكلاسيكية الغربية، و الموسيقي العربية الكلاسيكية، والفئية لفعرق الثرقية.

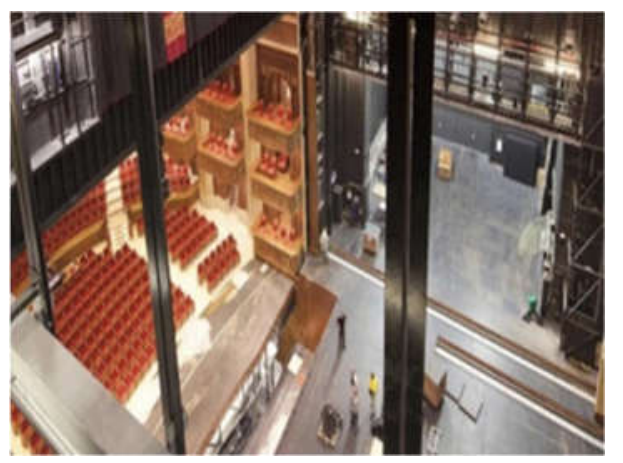

الصورة توضح علاقة المنصة مع الجيوب و البرج المسرحي، فضلا

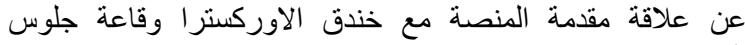

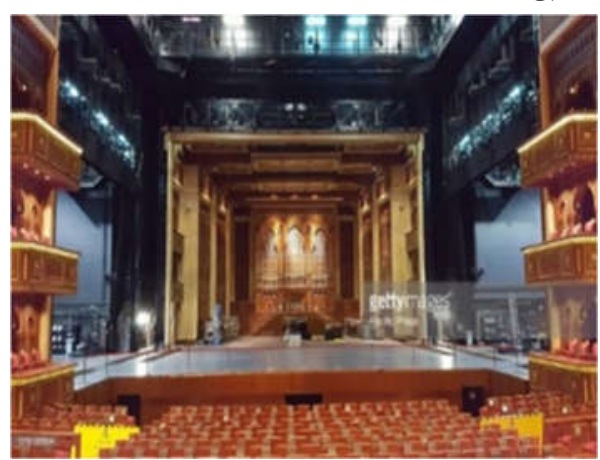

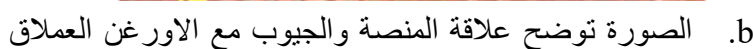
و النحابه على سكلك حديدية وخزنة في خلفية المنصة.

$$
\text { الثكل (20): يوضح منصة دار الاوبرا السلطانية. }
$$
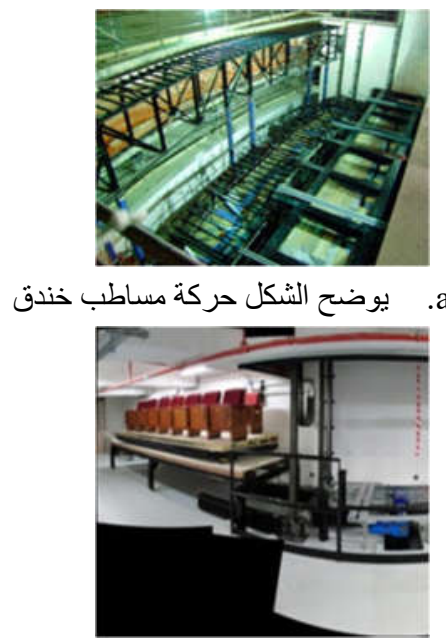

b . يوضح الثكل منظومة تحريك مقاعد المشاهدين و الر افعة الخاصة بـه

الثكل (21): يوضح منظومات مصاعد الاوركستر ا، و ونظومة تحريك الك الكية صفوف مقاعد المشاهدين في دار الاوبرا السلطانية.

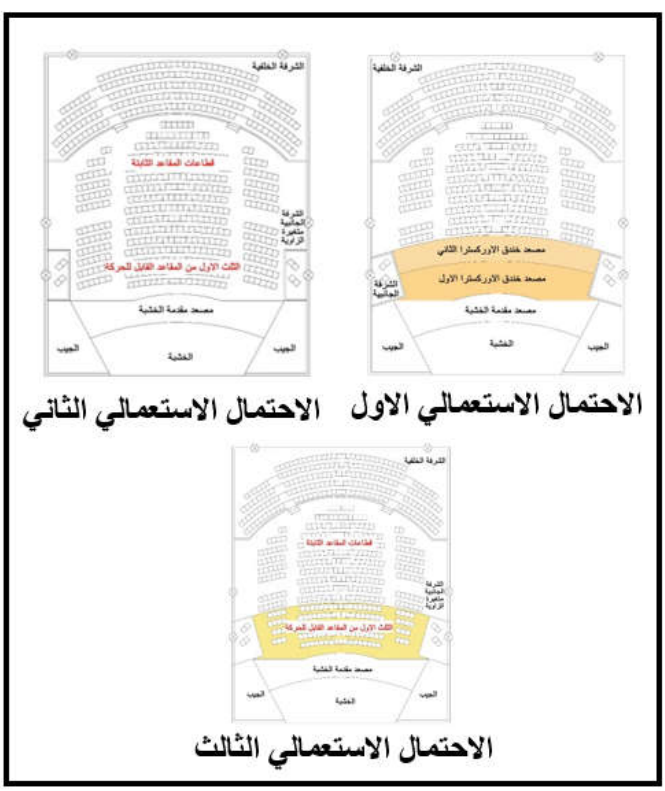

الشكل (19): الاحتمالات الاستعمالية لار الاوبر ا السلطانية

الجهة المصممة: تم تصميم دار الاوبرا من قبل شركه (WATG) المتخصصة للحلول المعمارية.

الجهة المنفذة: شركة كارليون علوي.

الطاقة الاستيعابية للقاعة: تصل الطاقة الاستيعابية الى (1100) مقعد.

تتميز اوبرا مسقط بالتطور التكنولوجي، حيث تستضيف قاعة دار الاوبرا

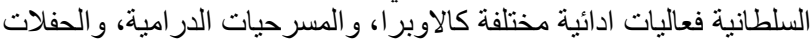

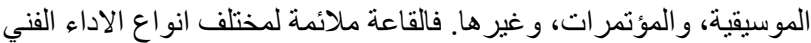

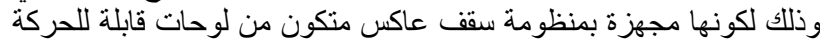

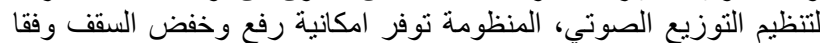

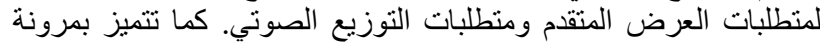

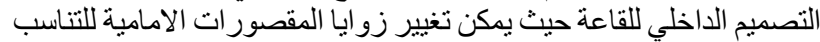

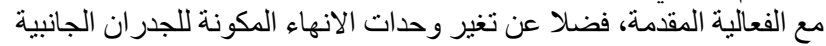

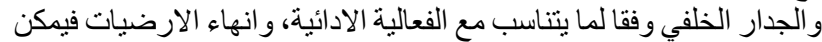

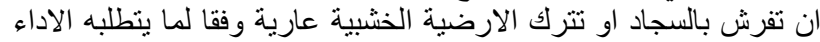

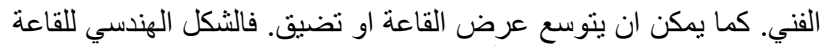

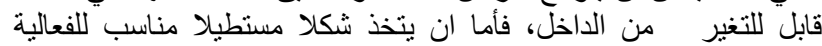

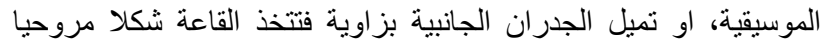

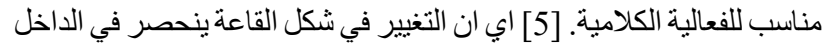

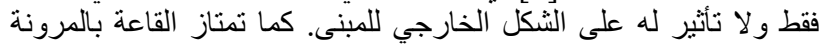

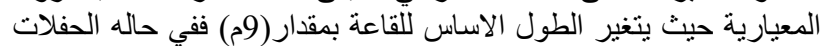

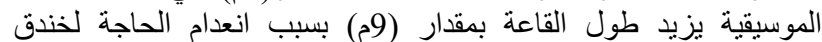

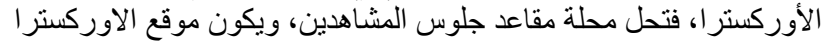

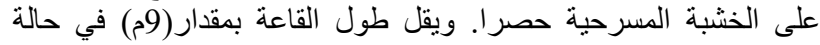

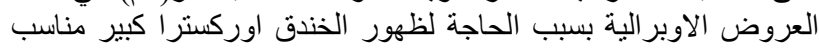

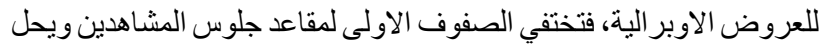

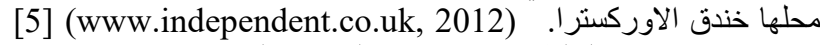

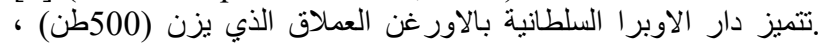

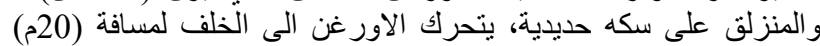

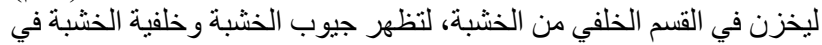

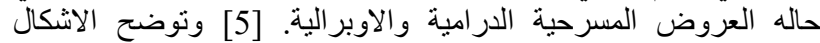
19,20,21 الاحتمالات الاستخدامية للقاعة وحسب الألئ الاتي:

الاحتمال الاستعمالي الأول: في حالة العروض الدر امية والاوبر الية،

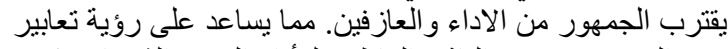

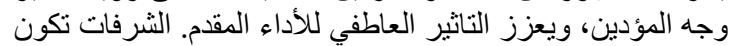

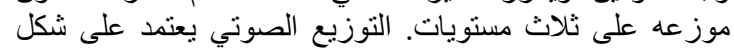


جدول (4): تطبيق مفردات ومؤشر ات الإطار النظري على دار الاوبرا السلطانية.

\begin{tabular}{|c|c|c|c|c|c|c|c|c|}
\hline \multicolumn{5}{|c|}{ التقييم } & \multirow[b]{2}{*}{ 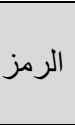 } & \multirow[b]{2}{*}{ مقومات المؤشر } & \multirow[b]{2}{*}{ مؤشر ات القيم الممكنة } & \multirow{2}{*}{ الرئيسة المفردة } \\
\hline ضديف & ضعيف & متوسط & جيد & جدا & & & & \\
\hline & & & & - & 1.1 & و الالكترونية و الارضيات المنصة الهيدروليكية المتحركة وفقا & مكننة تحريك الارضيات & $\frac{\overline{3}}{\frac{7}{2}}$ \\
\hline & & & & - & 1.2 & و إمكانية غلق الخندق العازفيز في في الخندق للمنصة او & مكننة موقع الأوركستر ا & $\overline{3}$ \\
\hline & & & & - & 1.3 & لتلبية نوع الفعالية & إمكانية تغيير عرض اطار & 等 \\
\hline & & & - & & 1.4 & المعايير البعدية للقاعة وحسب نوع الفعالية & المرونة المعيارية للقاعة & $\overline{3}$ \\
\hline & & & - & & 1.5 & 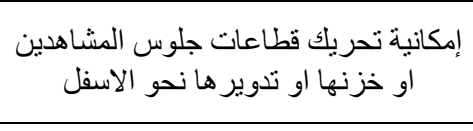 & 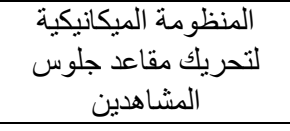 & \\
\hline & & & - & & 2.1 & لتغير حجم القاعة وتوفير زمن اللتباسية اللترديد & منظومة تحريك السقف & \\
\hline & & & - & & 2.2 & لتعديل زمن الترديد بما يتناسب مع الفعالية & و الثير نسب المواد التونة لضمان & प̄ \\
\hline & & & & - & 2.3 & الفعاليات الادائية لضمل الضمان لكل نوع الانعكاسات & 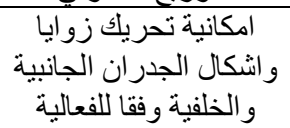 & 雪 \\
\hline & & & - & & 2.4 & القاعة المسرحية اضافة حجم فضائي علوم بزمن الترديد في & وحجم حجم فضاءي علو & 3 \\
\hline & & & & - & 2.5 & 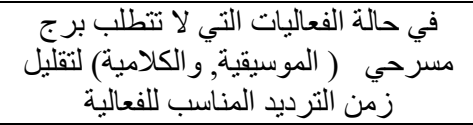 & المكانية عزل البرج & \\
\hline
\end{tabular}

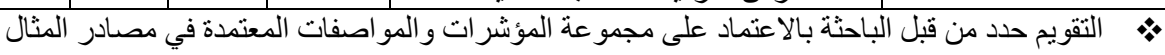

(او لا) النتائج المرتبطة بمفردة (استخدام المكننة في التغيير الاستعمالي):

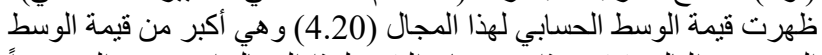

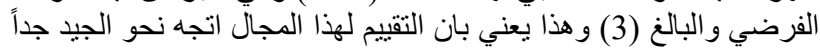

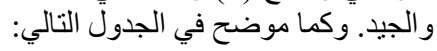

نتائج التطبيق على العينة الدراسية وتعليل النتائج

.9 تتناول هذه الفقرة تحليل نتائج التطبيق العملي على العينة الدراسية، وضمن

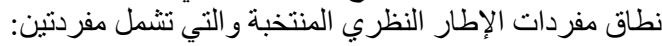

جدول (5): النسب و الوسط الحسابي لمجال استخدام المكنة في التغيير الاستعمالي

\begin{tabular}{|c|c|c|c|c|c|c|}
\hline الحسابي & ضديف & ضعيف & متوسط & جيذ & جيد جداً & المؤشرات \\
\hline 4.75 & -- & -- & -- & $\% 25$ & $\% 75$ & مكننة تحريك الارضيات \\
\hline 4.75 & -- & -- & -- & $\% 25$ & $\% 75$ & مكننة موقع الاوركستر ا \\
\hline 4.00 & $\% 25$ & -- & -- & -- & $\% 75$ & امكانية تغيير عرض اطار الفتحة \\
\hline 3.50 & $\% 25$ & -- & -- & $\% 50$ & $\% 25$ & المرونة المعيارية للقاعة \\
\hline 4.00 & -- & $\% 25$ & -- & $\% 25$ & $\% 50$ & المنظاهدينة الميكانيكية لتحريك مقاعد جلوس \\
\hline 4.20 & & & & & & المجموع \\
\hline
\end{tabular}

(ثانيا) النتائج المرتبطة بمفردة (امكانية التغيير الاستعمالي): ظهرت قيمة

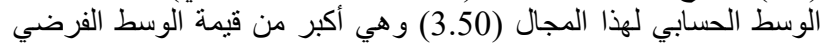

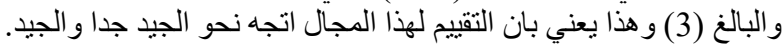


جدول (6): النسب و الوسط الحسابي لمجال استخدام المكنة في التغيير

\begin{tabular}{|c|c|c|c|c|c|c|}
\hline الحسابي & ضديف & ضعيف & متوسط & جيد & جيد جداً & المؤشرات \\
\hline 3.75 & -- & -- & $\% 25$ & $\% 75$ & -- & منظومة تحريك السقف \\
\hline 3.25 & -- & $\% 25$ & $\% 25$ & $\% 50$ & -- & تلغير نسب الصوتي اد الماصة و المو اد العاكسة لضمان \\
\hline 3.00 & $\% 50$ & -- & -- & -- & $\% 50$ & والخانفية وفقا للفعالية زوايا و واثكال الجدران الجانبية \\
\hline 2.50 & $\% 25$ & $\% 25$ & $\% 25$ & $\% 25$ & & وجود حجم فضائي علوي \\
\hline 5.00 & -- & -- & -- & -- & $\% 100$ & امكانية عزل البرج المسرحي \\
\hline 3.50 & & & & & & المجموع \\
\hline
\end{tabular}

$$
\begin{aligned}
& \text { b . مكننة موقع الاوركسترا. } \\
& \text { c امكانية تغيير عرض إطار الفتحة. }
\end{aligned}
$$

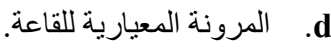

الشكل (23): يوضح القيمة التي حققها كل مؤشر. مما يشير الى نجاح مفردة (استخدام المكننة في التغيير الاستعمالي) عن طرئ التفريق العلاقة بين

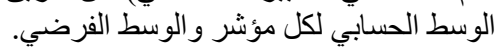

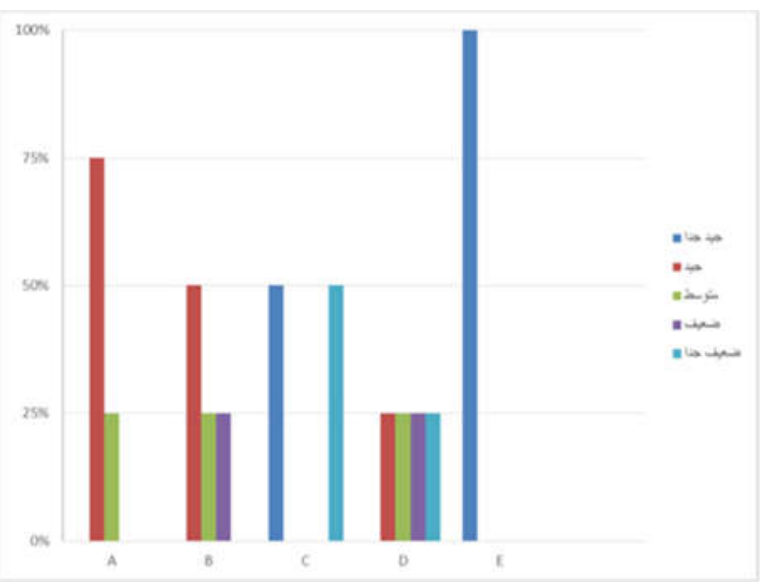

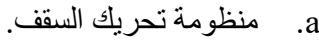

b تغيير نسب المواد الماصة والمواد العاكسة لضمان التوزيع الصوتي.

c امكانية تحريك زوايا واشكال الجدران الجانبية والخلفية وفقا

$$
\text { للفعالية. }
$$

d . وجود حجم فضائي علوي. d

e امكانية عزل البرج المسرحي.

الشكل (24): يوضح النسب المئوية المختلفة التي حقتهها المؤشر ات في التئي الدراسة التطبيقية على العينة الدراسية.

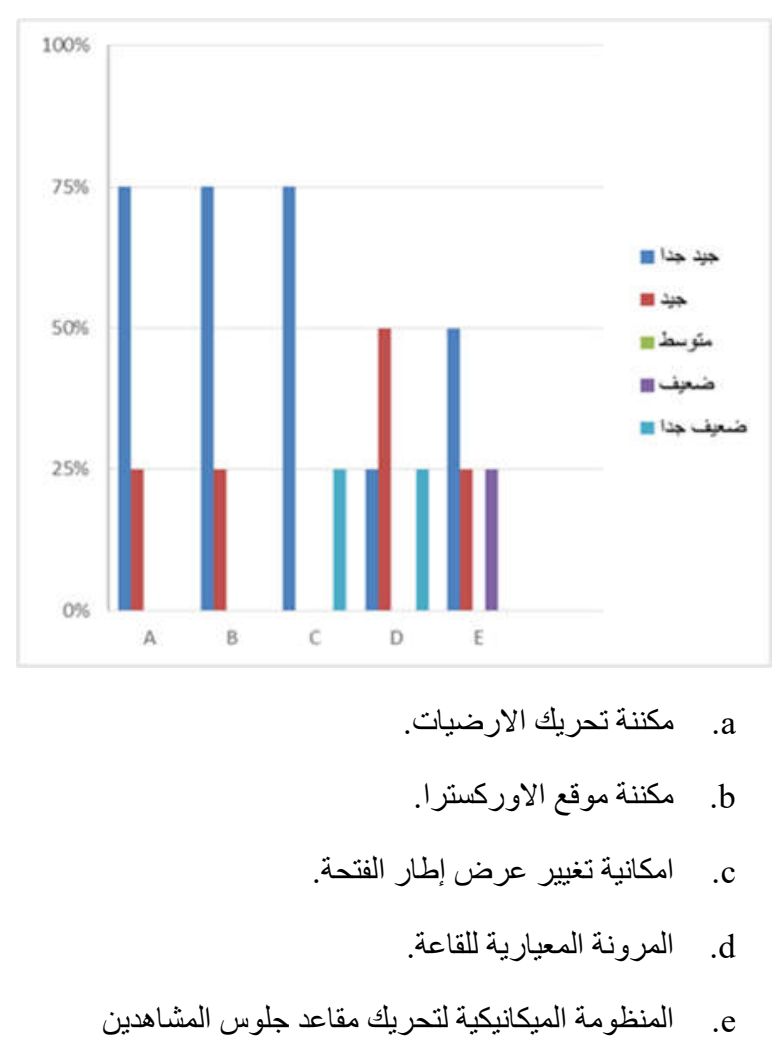

الثكل (22): يوضح النسب المئوية المختلفة التي حققتها المؤشر ات في الدراسة التطبيقية على العينة الدر اسية.

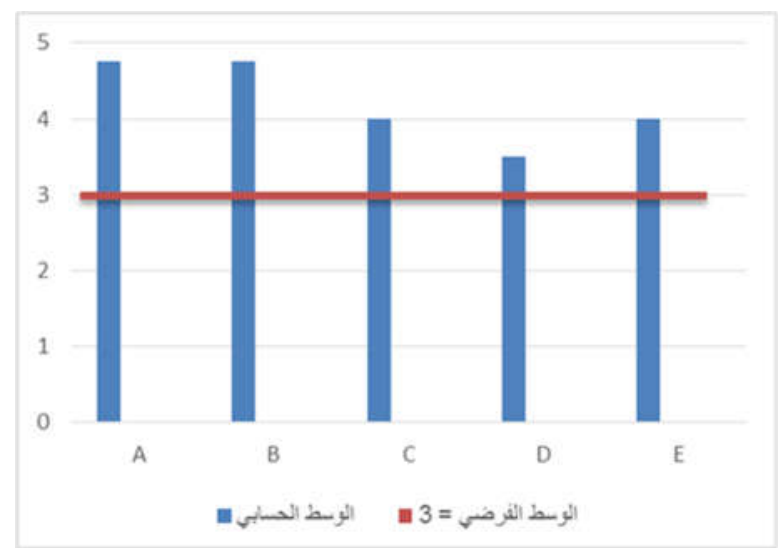

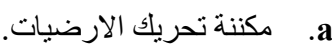




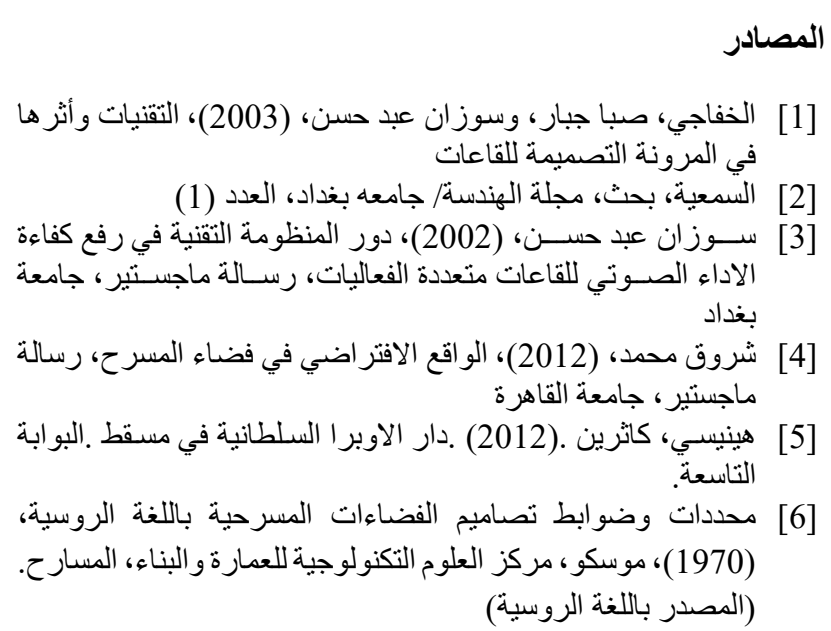

\section{Refrences}

[7] Appleton, Ian. (2008). Building for the Performing Arts.

[8] Atkins. (2016). How Atkins Made Dubai Opera A Landmark.

[9] Consulting, D. G. (2013). Beauty Within Capacity And Functionality Have Been Exploited To Create A State-Of-The-Art, Multi-Functional Creative Space For Performers In Seville. Auditoria, 89, 90.

[10] Dechiara, Joseph. \& Crosbie, Michael. (2001). TimeSaver Standerd for Building Types.

[11] Georgy.Izenour. (1996). Theater Design.

[12] Georgy, Olenin. (2016). Design Of Hydraulic Scissors Lifting Platform. Finland: Saimaa University of Applied Sciences.

[13] Ham, Rodrick. (1988). Theatres Palnning Guidance for Design\& Adaptation. London: Butterwoth Architecture.

[14] Holden, Mark. (2016). Acoustics of Multi-Use Art Centres.

[15] Idibri. (2011). Acoustic Design of the Royal Opera House Muscat.

[16] Ogawa, Toshiro. (2001). Theatre Engineering and Stage Machinery.

[17] Strong, Judith. (2010). Theatre Buldings A Design Guide.

[18] The Kremlin Palace of Congresses. (1965). Moscow.

[19] Lmn Architecture+Marmon Mok. (2014), Tobin Center for the Performing Arts.

[20] www.britannica.com

[21] www.dubaiopera.com

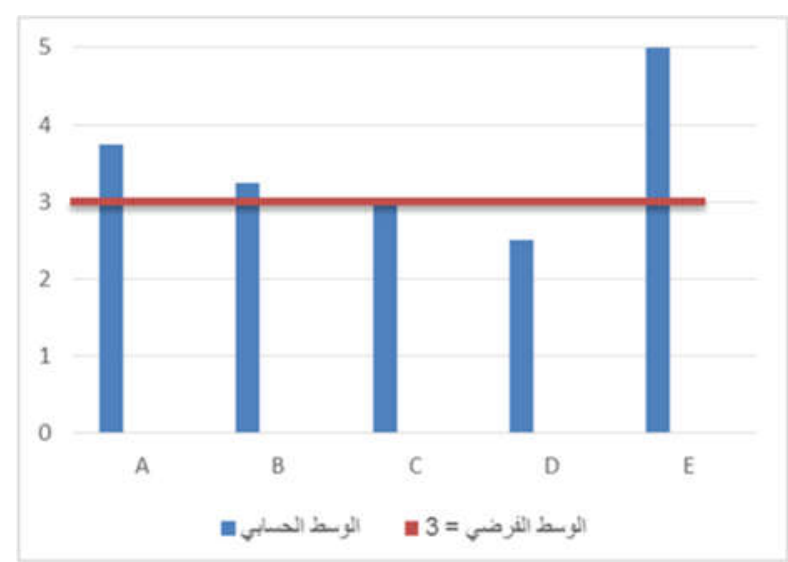

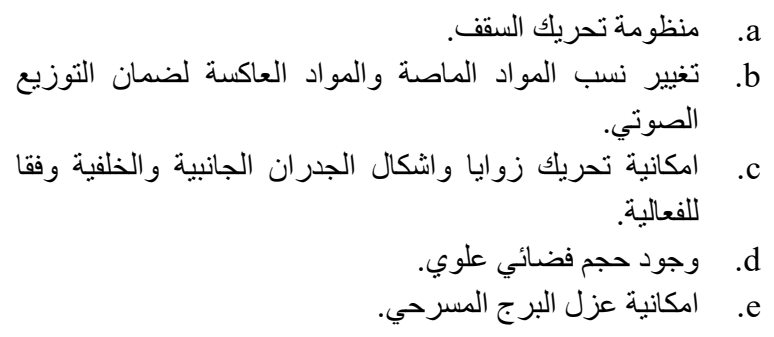

الشكل (25): يوضح القيمة التي حققها كل مؤشر . حيث يوضح ان ان مؤشر

(وجود حجم فضائي علوي) حقق قيمة أدني من قيمة الوسط الفرئ لفرضي.

10. الاستتناجات

1. ساعدت التقنيات الحديثة على توفير منطلبات الأنماط الوظيفية

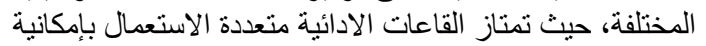

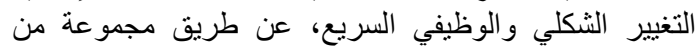
المنظومات الآلكترونية و الميكانيكية.

الهدف من انشاء المسارح الثاملة هو تامين فضاء موحد في الماءي

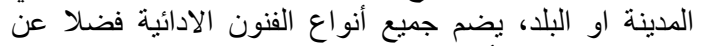

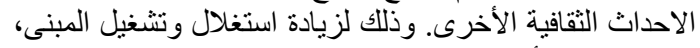

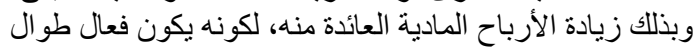
العام.

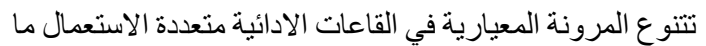

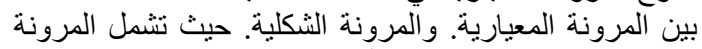

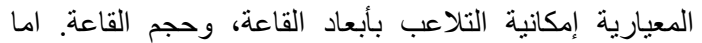

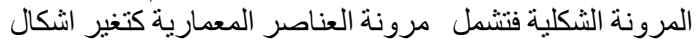

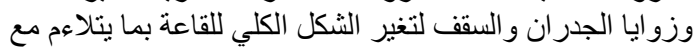

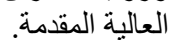

4. يظهر ان خاصية عزل البرج المسرحي تتوفر في جميع امثلة

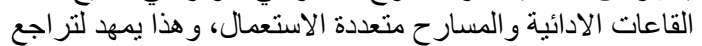

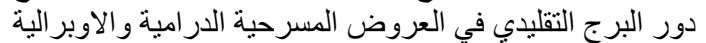
نتيجة لتطور التقنية الحديثة.

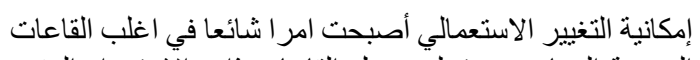

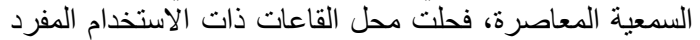

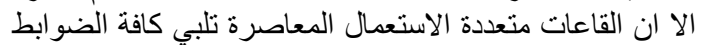

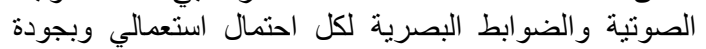
عالية.

\section{4}


[24] www.radiomarconi.

[25] www.galasystems.com
[22] www.Theatreprojects.Com

[23] www.radiomarconi.it.

\title{
The Role of Automation in Achieving Integration and Flexibilty in Multi-Use Auditoriums
}

\author{
Shahad Waqid Salih",*, and Bahjat Rashad Shaheen ${ }^{2}$ \\ ${ }^{1}$ Department of Architecture, University of Baghdad, Baghdad, Iraq, arch.shahadwakid@gmail.com \\ ${ }^{2}$ Department of Architecture, University of Baghdad, Baghdad, Iraq, bahjatsha@yahoo.com \\ * Corresponding author: Shahad Waqid Salih, arch.shahadwakid@gmail.com \\ Published online: 30 June 2019
}

Abstract-Modern techniques and technology are introfuced as an effictove factor in achiving the flexible use and in changing the foem and the utilization of the auditoriums and the stage eeasily. Which helped the emergance and spread of new types of performance events in one place. The orign of ghese auditoriums return to Gropius's tatal theatre at the beginning of the $29^{\text {th }}$ centuey. Modern technologies include mechanization systems foe floor, wall, and ceiling. The research problem focuse on the lake of available studies on the impact of modern technology and mechanization on the intgration of the use of the multi-use auditoriums. Thus the research amis to determining the role of the floor automation in the auditorium and the stage to achieve functional intgration (dramatic, musical, operatic, ect.) in one. The research suggests that the flooe automation in multi-use auditoriums if akey factor in achieving different uses. The research review a number of examples of multi-use auditoriums of the $20^{\text {th }}$ and the $21^{\text {st }}$ centuryillustrates the evolution of this tupe of auditoriums and the impact of mechanication and technology development.

Keywords- Multi-use auditoriums, modern techniques, automation systems. 